Journal for

ImmunoTherapy of Cancer

\title{
Functional and mechanistic advantage of the use of a bifunctional anti-PD-L1/ IL-15 superagonist
}

Karin M Knudson, Kristin C Hicks, Yohei Ozawa, Jeffrey Schlom (D), Sofia R Gameiro

To cite: Knudson KM, Hicks KC, Ozawa Y, et al. Functional and mechanistic advantage of the use of a bifunctional anti-PD-L1/ IL-15 superagonist. Journal for ImmunoTherapy of Cancer 2020;8:e000493. doi:10.1136/ jitc-2019-000493

- Additional material is published online only. To view, please visit the journal online (http://dx.doi.org/10.1136/jitc2019-000493).

JS and SRG contributed equally.

Accepted 11 March 2020

Check for updates

(C) Author(s) (or their employer(s)) 2020. Re-use permitted under CC BY-NC. No commercial re-use. See rights and permissions. Published by BMJ.

Laboratory of Tumor Immunology and Biology, Center for Cancer Research, National Cancer Institute, Bethesda, Maryland, USA

Correspondence to Dr Jeffrey Schlom; schlomj@mail.nih.gov

\section{ABSTRACT}

Background Anti $(\alpha)$-programmed cell death-1 (PD1)/programmed death-ligand 1 (PD-L1) monotherapy fails to provide durable clinical benefit for most patients with carcinoma. Recent studies suggested that strategies to reduce immunosuppressive cells, promote systemic T-cell responses and lymphocyte trafficking to the tumor microenvironment (TME) may improve efficacy. $\mathrm{N}-809$ is a first-in-class bifunctional agent comprising the interleukin (IL)-15 superagonist N-803 fused to two $\alpha$ PD-L1 domains. Thus, $\mathrm{N}-809$ can potentially stimulate effector immune cells through IL-15 and block immunosuppressive PD-L1. Here, we examined the antitumor efficacy and immunomodulatory effects of $\mathrm{N}-809$ versus $\mathrm{N}-803+\alpha \mathrm{PD}-\mathrm{L} 1$ combination.

Methods The ability of N-809 to block PD-L1 and induce IL-15-dependent immune effects was examined in vitro and in vivo. Antitumor efficacy of $\mathrm{N}-809$ or $\mathrm{N}-803+\alpha \mathrm{PD}-\mathrm{L} 1$ was evaluated in two murine carcinoma models and an extensive analysis of immune correlates was performed in the tumor and tumor-draining lymph node (dLN).

Results We demonstrate that N-809 blocks PD-L1 and induces IL-15-dependent immune effects. N-809 was well-tolerated and reduced $4 \mathrm{~T} 1$ lung metastasis, decreased MC38 tumor burden and increased survival versus $\mathrm{N}-803+\alpha \mathrm{PD}-\mathrm{L} 1$. Compared with $\mathrm{N}-803+\alpha \mathrm{PD}-\mathrm{L} 1$, $\mathrm{N}-809$ enhanced natural killer (NK) and $\mathrm{CD}^{+} \mathrm{T}$-cell activation and function in the $\mathrm{dLN}$ and TME, relating to increased gene expression associated with interferon and cytokine signaling, lymphoid compartment, costimulation and cytotoxicity. The higher number of TME $\mathrm{CD}^{+} \mathrm{T}$ cells was attributed to enhanced infiltration, not in situ expansion. Increased TME NK and CD8 ${ }^{+}$T-cell numbers correlated with augmented chemokine ligands and receptors. Moreover, in contrast to N-803+ $\alpha$ PD-L1, N-809 reduced immunosuppressive regulatory $\mathrm{T}$ cells $\left(\mathrm{T}_{\text {reg }}\right)$, monocytic myeloid-derived suppressor cells (M-MDSC) and M2-like macrophages in the TME.

Conclusions Our results suggest that $\mathrm{N}-809$ functions by a novel immune mechanism to promote antitumor efficacy. Foremost, N-809 enhances intratumoral lymphocyte numbers by increasing trafficking via altered chemokine levels in the TME and chemokine receptor expression on $\mathrm{CD}^{+} \mathrm{T}$ cells and NK cells. In addition, N-809 reduces immunosuppressive and pro-tumorigenic immune cells in the TME, including $\mathrm{T}_{\text {reg }}$, M2-like macrophages and M-MDSC. Overall, these novel effects of N-809 promote an inflamed TME, leading to lower tumor burden and increased survival. These results provide mechanistic insight and rationale supporting the potential clinical study of $\mathrm{N}-809$ in patients with carcinoma.

\section{INTRODUCTION}

While the use of single-agent immunotherapies, in particular immune checkpoint inhibitors, can produce durable and effective responses in some patients, clinical benefit for most patients with carcinoma is minimal. ${ }^{1}$ This is due to multiple factors, including tumor heterogeneity, the immunosuppressive nature of the tumor microenvironment (TME) and innate or acquired resistance to treatment. ${ }^{1}$ In order to improve patient response rates, immunotherapy combinations are used to target distinct components of the tumor/immune system interaction. Recent studies have demonstrated that decreasing the number of immunosuppressive cells, systemic activation of effector immune cells and altered lymphocyte migration to the TME, not in situ expansion, mediate optimal antitumor responses. $^{2-6}$

The combination of immunotherapies that decrease immunosuppression and activate immune effector cells may improve antitumor efficacy and induce the aforementioned immune effects. Anti $(\alpha)$-programmed cell death-1 (PD-1)/programmed cell deathligand 1 (PD-L1) antibodies decrease immune suppression by preventing the interaction of PD-L1 expressed on tumor or suppressive immune cells with PD-1 on natural killer (NK) and T cells. PD-1 ligation reduces NK and T-cell maturation, proliferation and effector function. ${ }^{6}$ In addition, $\alpha$ PD-L1 antibodies can decrease the number of and/or reprogram immunosuppressive immune cells like regulatory $\mathrm{T}$ cells $\left(\mathrm{T}_{\mathrm{reg}}\right)$ and $\mathrm{M} 2$ macrophages. ${ }^{4}$ M2 macrophages are emerging as an important suppressive cell type, and therapies that skew these cells to an antitumor M1 phenotype are of particular interest. Overall, 
PD-1/PD-L1-targeted antibodies have increased patient survival in carcinomas with high mutational burden such as melanoma, ${ }^{7}$ lung cancer ${ }^{8}$ and bladder cancer, ${ }^{9}$ but most patients with carcinoma fail to respond to PD-1/ PD-L1 blockade.

Interleukin (IL)-15, on the other hand, is an immuneactivating cytokine that promotes the systemic expansion and activation of NK and $\mathrm{CD} 8^{+} \mathrm{T}$ cells. ${ }^{10}$ Clinically, administration of recombinant IL-15 (rIL-15) promoted hyperproliferation and activation of $\mathrm{NK}$ and $\mathrm{CD}^{+} \mathrm{T}$ cells. ${ }^{11}{ }^{12}$ However, the high doses required to induce immune changes resulted in dose-limiting toxicities with no clinical response observed. ${ }^{11}{ }^{12}$ To promote patient responses with less toxicity, new IL-15 agents were developed. N-803 is an IL-15 superagonist (IL-15 N72S/ IL-15R $\alpha$ Sushi complex) that enhances $\mathrm{CD} 8^{+} \mathrm{T}$-cell and NK cell activation, proliferation, cytotoxicity and survival versus rIL-15, leading to improved antitumor responses preclinically. ${ }^{10} 13$ While N-803 significantly expanded patient $\mathrm{NK}$ and $\mathrm{CD}^{+} \mathrm{T}$ cells and was well-tolerated, it demonstrated limited clinical efficacy. ${ }^{11}{ }^{14}$ However, $\mathrm{N}-803$ in combination with an $\alpha \mathrm{PD}-\mathrm{L} 1 / \mathrm{PD}-1$ antibody showed clinical promise. A recent phase Ib study in non-small cell lung cancer reported that $\mathrm{N}-803$ and oPD-1 antibody nivolumab was well-tolerated, and $29 \%$ of patients, including 3/11 (27\%) patients previously treated but progressing with $\alpha \mathrm{PD}-1$, exhibited an objective response. ${ }^{15}$ Similarly, the combination of N-803+ + PD-L1 demonstrated improved antitumor efficacy in murine carcinoma models, including $\alpha$ PD-L1-refractory tumors versus either monotherapy. ${ }^{16}$ This efficacy was attributed to improved systemic $\mathrm{CD} 8^{+} \mathrm{T}$-cell and NK cell responses. ${ }^{16}$ However, the effect of N-803+ $\alpha$ PD-L1 on lymphocyte trafficking, an emerging paradigm important for efficacy, ${ }^{235}$ was not explored.

Other promising treatment strategies include bifunctional molecules, a novel class of immunotherapeutics that allows for interaction with two targets using a single agent. Bifunctional molecules have the potential to increase localization of an agent to the TME or immune cell of choice, leading to enhanced local effects, reduced systemic toxicity and/or for dual suppression and/or activation of immune pathways. ${ }^{16-19}$ Preclinical studies demonstrated that some bispecific molecules increased antitumor efficacy versus a similar immunotherapy combination, ${ }^{20}$ thus a potential for clinical advantage. Recently, $\mathrm{N}-809$, a bispecific fusion protein consisting of N-803 fused to two single chain $\alpha$ PD-L1 variable region $(\mathrm{ScFv})$ domains, was described. N-809 was able to block human PD-L1 and stimulate human immune cells via the IL-15 superagonist in vitro. ${ }^{21}$ A preliminary study suggested that $\mathrm{N}-809$ had antitumor efficacy in a murine tumor model. ${ }^{21}$ The mechanisms of action of N-809 and its therapeutic advantage relative to $\mathrm{N}-803+\alpha \mathrm{PD}-\mathrm{L} 1$ combination were not examined.

Here, for the first time, we compare the antitumor efficacies of $\mathrm{N}-809$ versus N-803+ $\alpha \mathrm{PD}-\mathrm{L} 1$ in murine carcinoma models. In addition, we perform a comprehensive immune analysis in the tumor and periphery. We describe the novel immune-mediated mechanism of action of $\mathrm{N}-809$ as compared with $\mathrm{N}-803+\alpha \mathrm{PD}-\mathrm{L} 1$, including its effects on immunosuppressive immune cells and effector cell activation and migration.

\section{METHODS \\ Reagents}

Murine N-809 and N-803 (previously ALT-803) were generously provided by ImmunityBio under a Cooperative Research and Development Agreement with the National Cancer Institute. Murine N-809 consists of N-803, an IL-15 N72D/IL-15R $\alpha$ Sushi superagonist complex containing the Fc-domain of murine IgG2a fused to two anti-PD-L1 ScFv domains. $\alpha$ PD-L1 (10F.9G2) and CD8 (2.43) antibodies were from BioXcell. The NK depletion antibody (anti-asialo-GM1) was from Wako Chemicals. FTY720 was from Sigma.

\section{Mice}

Female Balb/c and C57BL/6 mice aged 6-10 weeks were obtained from NCI Frederick Cancer Research Facility and maintained under specific pathogen-free conditions in accordance with Association for Assessment and Accreditation of Laboratory Animal Care guidelines.

\section{Murine tumor cell lines and tumor studies}

4T1 triple negative (TN) breast carcinoma and Yac-1 lymphoma cells were obtained from American Type Culture Collection. MC38 colon carcinoma cells are previously described. ${ }^{22}$ All cell lines were cultured according to providers' instructions, determined as mycoplasma free by MycoAlert Mycoplasma Detection Kit (Lonza) and used at low passage number.

For antitumor studies, $4 \mathrm{~T} 1$ tumor cells $\left(5 \times 10^{4}\right.$, subcutaneously) were orthotopically implanted into the mammary

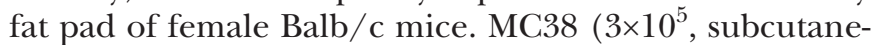
ously) tumor cells were implanted into the right flank of female C57BL/6 mice. Tumors were measured biweekly using digital calipers, and volumes were determined as (length ${ }^{2} \times$ width) $/ 2$. Mice were randomized based on tumor size and treatment initiated when tumors reached $50-100 \mathrm{~mm}^{3}$. Unless otherwise stated, mice received two doses of N-809 (subcutaneously) or two doses of N-803 $(0.3 \mu \mathrm{g}$, subcutaneously) plus $\alpha \mathrm{PD}-\mathrm{L} 1 \quad(200 \mu \mathrm{g}$, intraperitoneally). Quantification of 4T1 lung metastasis was performed as previously described. ${ }^{23}$

\section{Isolation of immune cells}

For all N-809 studies, unless otherwise stated, immune cells in the lymph nodes, spleen and tumors were isolated 2 days after the final treatment as previously described. ${ }^{16}$ Cell counts were performed using 123count eBeads (Thermo Fisher Scientific).

\section{Flow cytometry and antibodies}

Antibody labeling of cells for flow cytometry $\left(1-10 \times 10^{6}\right.$ immune cells) was performed using the BD Cytofix/ 
Cytoperm Kit (BD Biosciences) according to the manufacturer's instructions. Antibodies (online supplementary table S1) and matched isotypes were obtained from the listed manufacturers. Live/Dead Fixable Dead Cell Stain was from Invitrogen. Flow cytometry $\left(\geq 1 \times 10^{5}\right.$ events $)$ was performed on a BD LSRFortessa flow cytometer (Beckton Dickinson) and analyzed with FlowJo FACS Analysis Software V.9.9.6 (Treestar). Cell populations were identified as listed (online supplementary table S2). Expression of phenotypic proteins was determined by subtracting the respective isotype, set between $1 \%$ and $5 \%$ of the population.

\section{$\mathrm{CDB}^{+} \mathrm{T}$-cell restimulation}

Isolated immune cells were stimulated with $\alpha \mathrm{CD} 3$ (2C11, BD Biosciences) $+\alpha$ CD28 (37.51, BD Biosciences) as previously described. ${ }^{16}$ Frequency of interferon gamma $(\mathrm{IFN} \gamma)^{+}$ and/or tumor necrosis factor alpha $(\mathrm{TNF} \alpha)^{+}$cells were calculated by subtracting the non-stimulated controls.

\section{NK cell cytotoxicity assay}

NK cell killing of Yac-1 targets was determined as previously described. ${ }^{1624}$

\section{RNA extraction and NanoString analysis}

Tumor fragments were preserved in RNAlater (Thermo Fisher Scientific) and stored at $-80^{\circ} \mathrm{C}$. RNA was extracted using the RNeasy Mini Plus Kit (Qiagen) following the manufacturer's protocol. RNA purity was assessed on the Nanodrop One Spectrophotometer (Thermo Fisher Scientific) and Agilent Bioanalyzer (Agilent). RNA analysis was performed using the PanCancer Mouse IO 360 Panel and data analyzed using the nSolver Software and nCounter Advanced Analysis Software (NanoString). Heatmaps were generated using the Morpheus Software (Broad Institute) for the fold change of a given treatment over phosphate-buffered saline (PBS) calculated by NanoString analyses.

\section{Statistics}

Statistical analyses were performed in Prism V.7.0a or V.8.2 (GraphPad Software). Unless otherwise stated, data presented in bar graphs or scatter plots were analyzed using one-way analysis of variance (ANOVA) with Tukey's multiple comparisons. Two-way ordinary ANOVA was used to analyze tumor growth curves. Survival was analyzed using log-rank (Mantel-Cox) test. Outliers were identified using $\underline{\text { Robust regression and Outlier removal (ROUT }}$ test). Statistical significance was set at $\mathrm{p}<0.05$.

Additional materials and methods are described in online supplementary additional files.

\section{RESULTS}

\section{$\mathrm{N}-809$ binds to PD-L1 and has IL-15 activity in vivo and in} vitro

First, we validated PD-L1 binding ability and IL-15 activity of N-809. In vitro, N-809 bound to murine PD-L1 in a cell-free system (figure 1A) and on murine MC38 colon tumor cells (figure 1B) with similar affinity to a commercially available $\alpha$ PD-L1. In vivo administration of N-809 reduced detectable surface expression of PD-L1 on CD $45^{+}$ cells in MC38 primary tumor, draining and non-draining lymph nodes (LN) and spleen (figure 1C).

IL-15 is a NK cell prosurvival and proliferation-inducing factor. ${ }^{25}$ To determine IL-15 activity of N-809 in vitro, splenic NK cells were incubated with N-809 or N-803 and viability/proliferation was determined. Untreated NK cells did not survive (figure 1D). N-809 significantly enhanced NK cell viability/proliferation, although 41-fold less than N-803 (figure 1D). When bound to murine PD-L1, N-809 retained $75 \%$ of its IL-15 activity (figure 1E). N-809 also demonstrated IL-15-related activity in vivo, as shown by minor changes to $\mathrm{CD} 4^{+} \mathrm{T}$-cell number (figure $1 \mathrm{~F}$ ) and IL-15R $\beta$ expression (figure 1G) and major dosedependent alterations to $\mathrm{NK}$ and $\mathrm{CD} 8^{+} \mathrm{T}$ cells. $\mathrm{CD} 4^{+} \mathrm{T}$ cells are known to be less responsive than $\mathrm{NK}$ and $\mathrm{CD} 8^{+} \mathrm{T}$ cells to IL-15. ${ }^{25} \mathrm{~N}-809$ greatly enhanced NK cell number (figure 1H) and expression of IL-15R $\beta$ (figure 1I) and Ki67 (figure 1J). Similar effects were observed on $\mathrm{CD}^{+}$ $\mathrm{T}$ cells (figure $1 \mathrm{~K}-\mathrm{M}$ ). Together, these data demonstrate that the $\alpha$ PD-L1 and IL-15 components of N-809 are functional in vitro and in vivo.

\section{Subcutaneous administration of $\mathrm{N}-809$ induces antitumor efficacy against murine breast and colon carcinomas}

Clinically, $\alpha$ PD-L1 is administered intravenously ${ }^{9}$ while experimentally given intravenously or intraperitoneally. ${ }^{15} 16 \mathrm{~N}-803$ is given subcutaneously both in the clinic and experimentally. ${ }^{14-1626}$ Since N-809 consists of $\alpha$ PD-L1 and $\mathrm{N}-803$, we determined whether route of administration impacted antitumor efficacy. Subcutaneous and intraperitoneal administration of N-809 to $4 \mathrm{~T} 1$ tumor-bearing mice significantly reduced lung metastasis burden by $36 \%$ and $35 \%$, respectively (online supplementary figure S1a-c). As route of administration did not affect N-809 efficacy and N-803 subcutaneously is better tolerated clinically, ${ }^{14}{ }^{26} \mathrm{~N}-809$ was administered subcutaneously.

We also determined the optimal dose of N-809 for antitumor efficacy in the highly aggressive $4 \mathrm{~T} 1 \mathrm{TN}$ breast and MC38 colon carcinoma models. N-809 did not greatly affect primary 4T1 tumor growth at any dose (online supplementary figure $\mathrm{S} 1 \mathrm{a}, \mathrm{d}$ ), but $50 \mu \mathrm{g} \mathrm{N}-809$ induced the greatest reduction in $4 \mathrm{~T} 1$ lung tumor burden compared with 25 and $100 \mu \mathrm{g}$ N-809 (online supplementary figure $\mathrm{S} 1 \mathrm{~b}, \mathrm{c}, \mathrm{e}, \mathrm{f}$ ). In contrast, $100 \mu \mathrm{g} \mathrm{N}-809$ best decreased tumor burden and increased median overall survival (mOS) in MC38 tumor-bearing mice (online supplementary figure $\mathrm{S} 1 \mathrm{~g}-\mathrm{i})$. Thus, $\mathrm{N}-809$ was used at $50 \mu \mathrm{g}$ for $4 \mathrm{~T} 1$ tumor studies and $100 \mu \mathrm{g}$ for MC38 tumor studies.

\section{$\mathrm{N}-809$ improves antitumor efficacy versus $\mathrm{N}-803+\alpha \mathrm{PD}-\mathrm{L} 1$ combination}

Next, we compared the antitumor efficacy of N-809 versus $\mathrm{N}-803+\alpha \mathrm{PD}-\mathrm{L} 1$ in murine $4 \mathrm{~T} 1$ and MC38 tumor models, which are resistant to either $\alpha \mathrm{PD}-\mathrm{L} 1$ or N-803 monotherapy, respectively. ${ }^{16}$ Due to significant treatment-related 
A

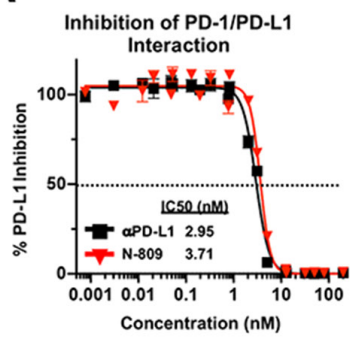

B

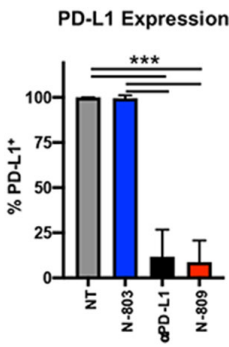

C

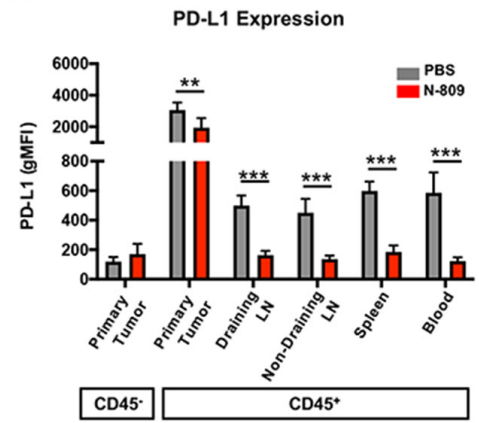

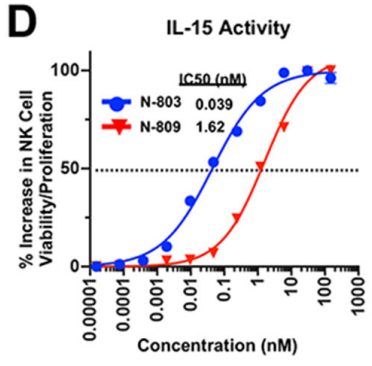

E

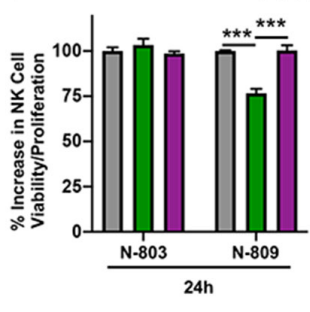

PD-L1/L-15 Bifunctional Activity

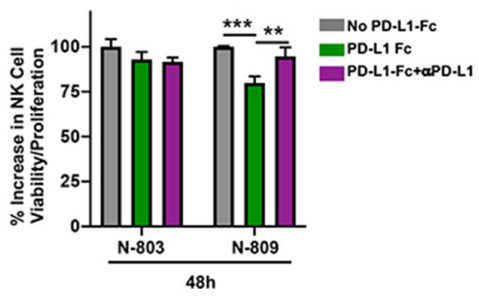

\section{F G}
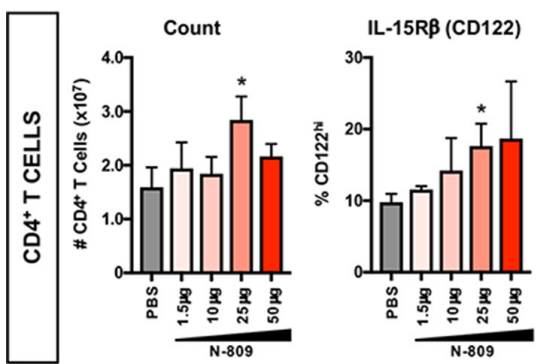

H

\section{I}
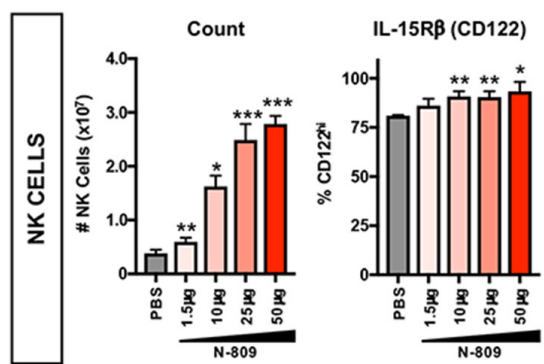

$\mathbf{J}$
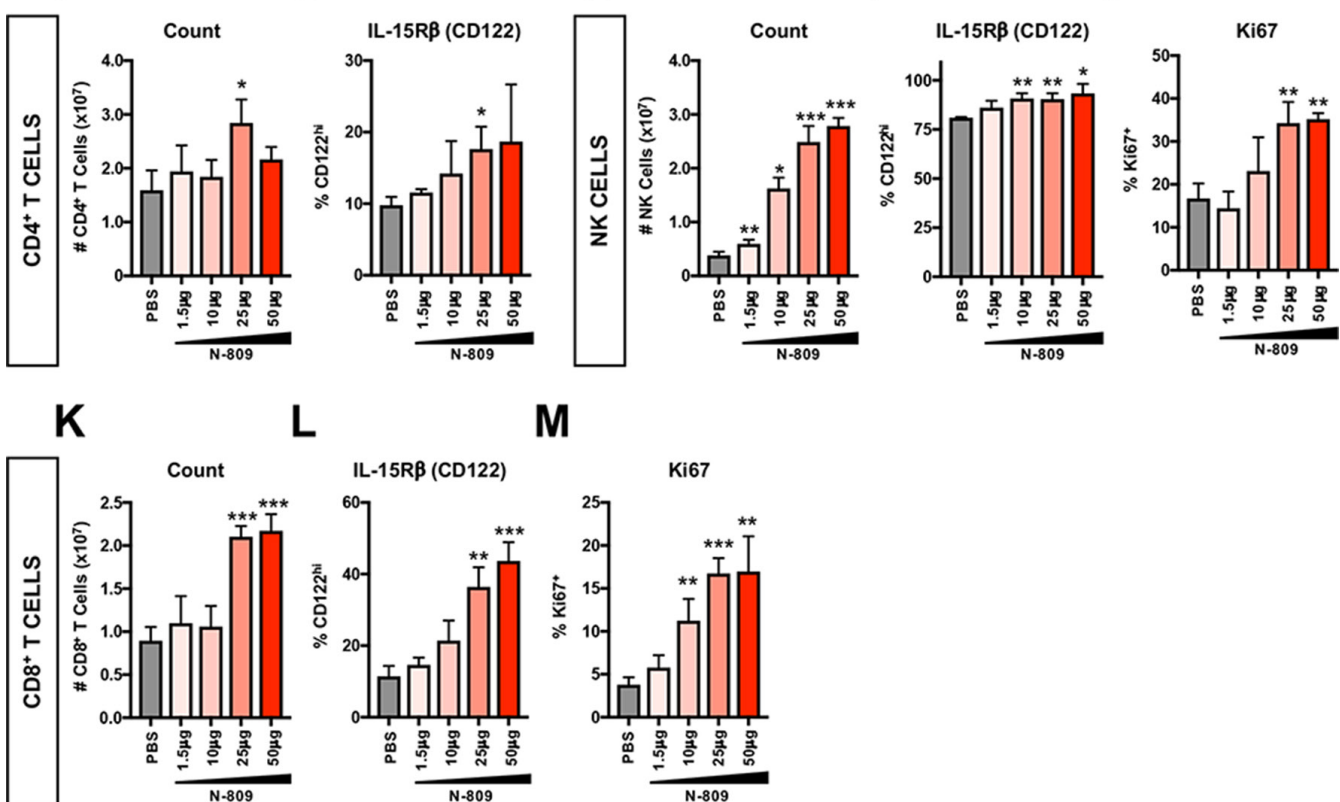

$\mathrm{IL}-15 \mathrm{R} \beta$ (CD122)

\section{M}
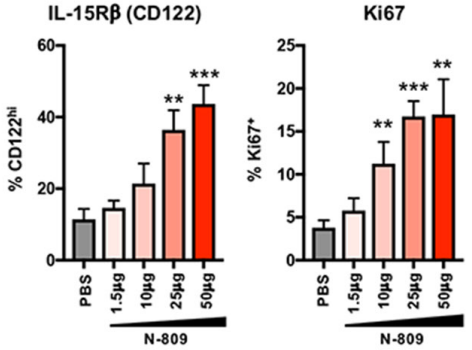

Figure $1 \mathrm{~N}-809$ binds to programmed death-ligand 1 (PD-L1) and displays interleukin (IL)-15 immune-related activity in vitro and in vivo. (A) Plate bound PD-L1-Fc was incubated with anti-PD-L1 ( $\alpha$ PD-L1) or N-809 prior to the addition of biotinylated programmed cell death-1 (PD-1). The amount of biotinylated PD-1 was quantified for \% PD-L1 inhibition (inset: IC50). Data are combined from two independent experiments. (B) MC38 tumor cells were treated with $100 \mathrm{nM}$ interferon (IFN) $\gamma$. After 24 hours, $1 \times 10^{6}$ cells were incubated for $30 \mathrm{~min}$ at $37^{\circ} \mathrm{C}$ with $1 \mathrm{nM} \mathrm{N}-803, \alpha \mathrm{PD}-\mathrm{L} 1$ or N-809. Unoccupied surface PD-L1 was detected by flow cytometry. Data are combined from two to three independent experiments. (C) $3 \times 10^{5} \mathrm{MC} 38$ tumor cells were implanted into the flank of female C57BL/6 mice. When tumor volumes reached $\sim 50 \mathrm{~mm}^{3}$, mice were treated at days 10 and 14 with $100 \mu \mathrm{g}$ $\mathrm{N}-809$ (subcutaneously). PD-L1 expression was detected by flow cytometry on CD45- and CD $45^{+}$cells 2 days after treatment. All statistics shown are two-tailed t-test of phosphate-buffered saline (PBS) vs $\mathrm{N}-809$ in the respective immune compartment. Data are from one experiment, $\mathrm{n}=6$ mice/group. (D) Splenic natural killer (NK) cells were incubated with $\mathrm{N}-803$ and $\mathrm{N}-809$ for 48 hours and viability/proliferation was measured using CellTiter-Glo (inset: IC50). Data are representative of five independent experiments. (E) Plate bound PD-L1-Fc was unblocked or blocked with $\alpha$ PD-L1. $200 \mathrm{nM} \mathrm{N}-803$ or N-809 was added for 30 min prior to measurement of splenic NK cell viability/proliferation using CellTiter-Glo. Data are from one experiment. (F-M) Naïve Balb/c mice were treated with N-809 (subcutaneously) on days 0 and 4. Splenic CD4 ${ }^{+} T$ cells $(F, G)$, NK cells (H-J) and CD8 ${ }^{+} T$ cells $(\mathrm{K}-\mathrm{M})$ were examined by flow cytometry 3 days after treatment. Graphs show CD4+ -cell number (F) and IL-15R 3 (CD122) expression (G), NK cell number (H) and IL-15R $\beta$ (I) or Ki67 (J) expression, and CD8 ${ }^{+}$T-cell number (K) and IL-15R 3 (L) or Ki67 (M) expression. All statistics shown are two-tailed t-test vs PBS. Data are from one experiment, $n=5$ mice/group. All graphs show mean \pm SD. ${ }^{*} \mathrm{P}<0.05,{ }^{* \star} \mathrm{p}<0.01,{ }^{* \star *} \mathrm{p}<0.001$. 
mortality of mice with high-dose N-803 (online supplementary figure $S 1 \mathrm{j}, \mathrm{k}$ ), we were unable to use equimolar doses of N-809 and N-803+ $\alpha$ PD-L1 (online supplementary table S3). Instead, N-809 was compared with $0.3 \mu \mathrm{g}$ $(15 \mu \mathrm{g} / \mathrm{kg}) \mathrm{N}-803$ and $200 \mu \mathrm{g}(10 \mathrm{mg} / \mathrm{kg}) \alpha \mathrm{PD}-\mathrm{L} 1$. These doses are similar to those used in the clinic ${ }^{91415}$ and have not been previously evaluated in murine tumor models.

$\mathrm{N}-809$ and N-803+ + PD-L1 were well tolerated in both tumor models, as neither 4T1 nor MC38 tumor-bearing mice significantly lost weight after treatment (online supplementary figure S2a,c). After N-809 treatment, 4T1 and MC38 tumor-bearing mice had increased inflammation in the lung (online supplementary figure S2b) or kidney, liver and lung (online supplementary figure S2d), respectively. However, these effects were transient and displayed no evidence of morbidity (online supplementary figure S2d).

We have previously demonstrated that N-803 increases systemic PD-L1 expression on $\mathrm{CD}_{4} 5^{+}$cells, in particular monocytic (M-MDSC) and granulocytic (G-MDSC) myeloid-derived suppressor cells. ${ }^{16}$ Furthermore, N-803 greatly enhances macrophage PD-L1 expression (online supplementary figure S3a). N-809 reduced detectable surface PD-L1 expression less than N-803+ $\alpha$ PD-L1 on $\mathrm{CD} 45^{-}$and $\mathrm{CD} 45^{+}$cells in the primary tumor and periphery of 4T1 (figure 2A) and MC38 (figure 2B) tumor-bearing mice, suggesting lower PD-L1 blockade by $\mathrm{N}-809$. However, N-809 induced greater antitumor efficacy versus $\mathrm{N}-803+\alpha \mathrm{PD}-\mathrm{L} 1$. N-803+ $\alpha$ PD-L1 significantly reduced $4 \mathrm{~T} 1$ lung tumor burden by $36 \%$ vs PBS, whereas $\mathrm{N}-809$ decreased lung metastasis by $60 \%$ (figure 2C-E). In addition, N-809 significantly reduced MC38 tumor burden (figure 2F,G) and increased mOS from 24 to 29 days (figure $2 \mathrm{H}$ ) versus N-803+ $\alpha$ PD-L1. N-809 cured $8 \%$ of MC38 tumor-bearing mice (figure 2G), and mice did not develop palpable tumors after rechallenge (figure 2I,J). Together, these data demonstrate that N-809 is welltolerated and has increased antitumor efficacy versus N-803+ $\alpha$ PD-L1.

\section{$\mathrm{N}-809$ induces a systemic and intratumoral immunostimulatory environment}

In order to dissect the mechanism of action of N-809, we first examined serum cytokine levels in MC38 tumor-bearing mice. Immunostimulatory cytokines IFN $\gamma$ (figure $3 \mathrm{~A}$ ) and $\mathrm{TNF} \alpha$ (figure 3B) were significantly elevated by N-809 compared with PBS and N-803+ $\alpha$ PD-L1. N-809 also elevated IL-10 (figure 3C), an immunosuppressive cytokine which counteracts high levels of IFN $\gamma$ and $\mathrm{TNF} \alpha,{ }^{27}$ but did not increase serum IL-6 (figure 3D), a known driver of IL-15associated toxicity. ${ }^{11}{ }^{26} \mathrm{~N}-803+\alpha \mathrm{PD}-\mathrm{L} 1$ did not increase serum cytokine levels compared with PBS (figure 3A-D).

Intratumoral cytokine signaling was examined by NanoString. Overall, N-809 induced greater changes to genes involved in interferon (figure 3E) and cytokine (figure $3 \mathrm{~F}$ ) signaling than N-803+ $\alpha$ PD-L1. Notably, $\mathrm{N}-809$ increased expression of IFN $\gamma$ targets (MHC class I genes $H 2-A a$ and $H 2-Q 10)$ and genes associated with positive regulation of IFN $\gamma$ signaling (Jak1 (JAK1), Ifngrl (IFN $\gamma \mathrm{RI})$ ). Many downregulated genes were type I IFN-related, including Irf7, Ifit1-3, Isg15, Rsad2, Oasl1, Oas1a, Oas2-3 (figure 3E). N-809 also increased gene expression related to immunostimulatory cytokines IL-2

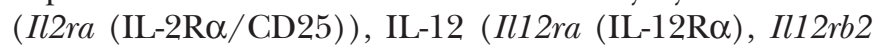
(IL-12RßII)) and IL-18 (Il18r1 (IL-18RI)) (figure 3F). $I l 2 r b$, a component of the IL-15 receptor (CD122/ IL-15R $\beta$ ), had the greatest upregulation of all cytokineassociated genes after N-809 treatment (figure 3F). Together, these results suggest that N-809 induces an immunostimulatory environment both systemically and in the TME.

\section{$\mathrm{N}-809$ enhances the ratio of effector to suppressive immune cells in the TME and draining LN}

Changes to cytokine levels and signaling suggested major alterations to the immune compartment by N-809, especially compared with N803+ $\alpha$ PD-L1. Supporting this, NanoString analysis of the tumor (figure 4A) showed an enrichment of genes associated with the lymphoid compartment (figure 4B), cytotoxicity (figure 4C), costimulation (figure 4D) and the myeloid compartment (figure $4 \mathrm{E}$ ) by N-809, not N-803+ $\alpha \mathrm{PD}-\mathrm{L} 1$. The most upregulated genes by N-809 were related to NK and $\mathrm{CD} 8^{+}$ T-cell cytotoxicity and infiltration, including Grzma (granzyme A), Prf1 (perforin) and Grzme (granzyme E), Cxcr3 (CXCR3), Tbx21 (T-bet), Lck (LCK) and Cd3e (CD3e) (figure 4A).

In order to confirm and expand these findings, we performed a comprehensive analysis of immune subsets in the TME by flow cytometry. Corroborating the gene expression results, NK (figure $4 \mathrm{~F}$ ) and $\mathrm{CD}^{+}$T-cell (figure 4G) numbers were significantly enhanced after $\mathrm{N}-809$ treatment while the number of $\mathrm{T}_{\text {reg }}$ (figure $4 \mathrm{H}$ ) and M-MDSC were decreased (figure 4J). Reduction in total macrophage numbers (figure $4 \mathrm{~K}$ ) was due to decreased immunosuppressive M2-like (figure 4M) but not pro-inflammatory M1-like (figure 4L) macrophages. N-809 did not alter CD4 ${ }^{+}$T-cell (online supplementary figure S3b) and G-MDSC (online supplementary figure S3c) numbers. Overall, N-809 promoted an inflamed TME by increasing the proportion of immune effector to suppressive cells, as shown by increased $\mathrm{CD} 8^{+} \mathrm{T}$ cell: $\mathrm{T}_{\text {res }}$ (figure 4I) and M1-like:M2-like macrophage (figure 4N) ratios. Other than reducing total macrophage numbers (figure 4K), although lesser than N-809, N-803+ $\alpha$ PD-L1 did not affect TME immune cell numbers (figure $4 \mathrm{~F}-\mathrm{N}$ ).

We also evaluated immune cell populations in the draining (d) LN. N-809 significantly enhanced NK cell (figure 4F), CD8 ${ }^{+}$T-cell (figure 4G) and $\mathrm{CD} 4^{+}$T-cell (online supplementary figure S3b) numbers. In contrast to the TME, $\mathrm{T}_{\text {reg }}$ (figure $4 \mathrm{H}$ ), M-MDSC (figure 4J) and total macrophage numbers (figure $4 \mathrm{~K}$ ) increased in the dLN with $\mathrm{N}-809$. The expanded total macrophage number (figure 4K) was due to increased M1-like (figure 4L), not M2-like (figure 4M), macrophages. G-MDSC were not affected by treatment (online supplementary figure 
A

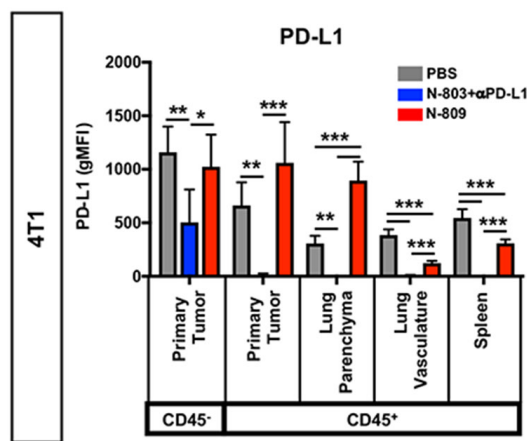

C

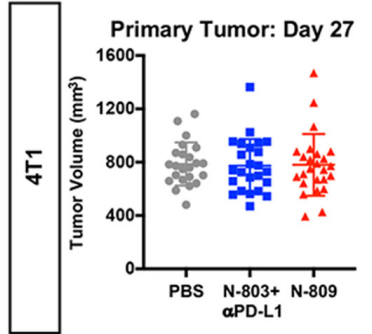

$F$

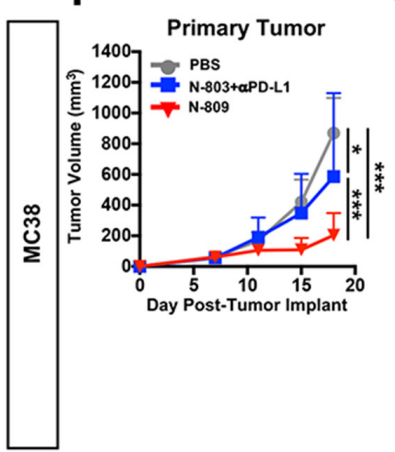

G

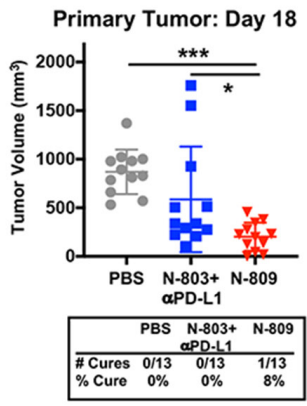

B

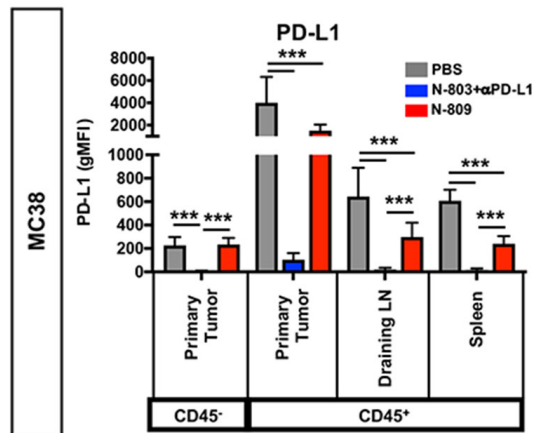

E
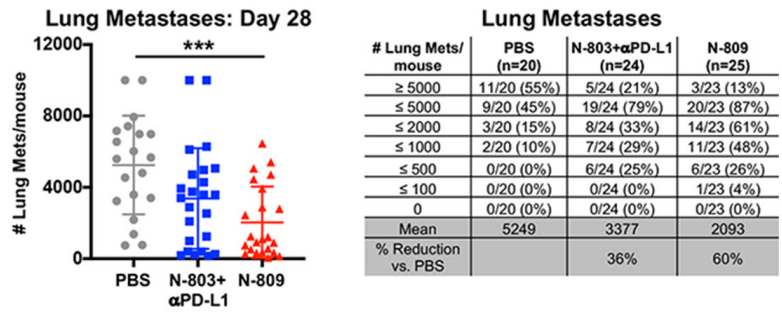

H

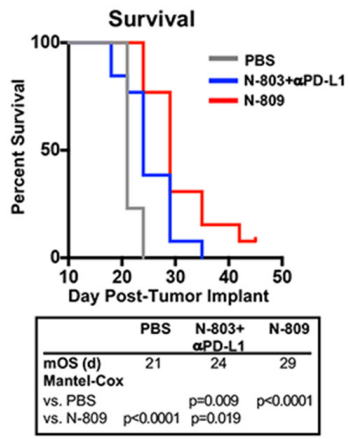

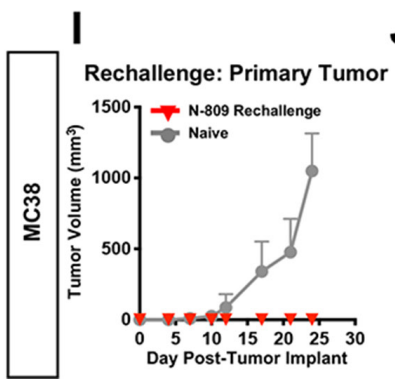

$\mathrm{J}$

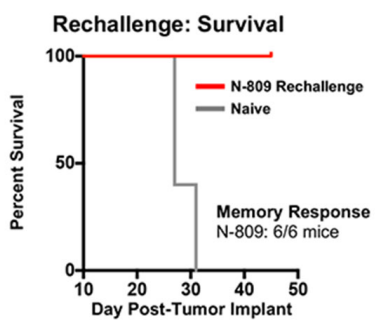

Figure $2 \mathrm{~N}-809$ decreases 4T1 lung metastasis and MC38 tumor burden and improves survival vs N-803+ $\alpha$ PD-L1. (A) $5 \times 10^{4} 4 \mathrm{~T} 1$ tumor cells were orthotopically implanted into female Balb/c mice. When tumor volumes reached $\sim 50 \mathrm{~mm}^{3}$, mice were treated at days 9 and 13 with $0.3 \mu \mathrm{g} \mathrm{N}-803$ (subcutaneously) $+200 \mu \mathrm{g} \alpha \mathrm{PD}-\mathrm{L} 1$ (intraperitoneally) or $50 \mu \mathrm{N}-809$ (subcutaneously). Programmed death-ligand 1 (PD-L1) expression was detected by flow cytometry on $\mathrm{CD}^{-} 5^{-}$and $\mathrm{CD} 45^{+}$ cells. Data are from one experiment, $n=5$ mice/group. (B) MC38 tumors were implanted as in figure 1 and mice were treated at days 8 and 12 with $0.3 \mu \mathrm{g} \mathrm{N}-803$ (subcutaneously)+200 $\mu \mathrm{g} \alpha \mathrm{PD}-\mathrm{L} 1$ (intraperitoneally) or $100 \mu \mathrm{g} \mathrm{N}-809$ (subcutaneously). PD-L1 expression was detected by flow cytometry on $\mathrm{CD} 45^{-}$and $\mathrm{CD} 45^{+}$cells. Data are combined from two independent experiments, $\mathrm{n}=5$ mice/group per experiment. (C-E) 4T1 tumors were implanted and mice were treated as in (A). Graphs show tumor volumes at day 27 post-tumor implant (C) and number of lung metastases in individual mice at day 28 post-tumor implant (D). (E) Table denotes the distribution of lung metastases number and \% reduction in mean vs phosphate-buffered saline (PBS). Data are representative of two independent experiments, $\mathrm{n}=20-25$ mice. $(\mathrm{F}-\mathrm{H}) \mathrm{MC} 38$ tumors were implanted and mice were treated as in (B). Graphs show primary tumor growth curves (F) and tumor volumes of individual mice at day 18 (inset: \% cured mice) (G). Graphs show mean \pm SD. $(H)$ Survival curves (inset: median overall survival $(m O S))$ show \% survival. Data are representative of two independent experiments, $\mathrm{n}=13$ mice. (I-J) At least 1 month after tumor resolution (days 52-92), cured mice and paired naiive C57BL/6 were implanted with $3 \times 10^{5}$ MC38 tumor cells. (I) Graph shows primary tumor growth curves. Graphs show mean \pm SD. (J) Survival curves (inset: \# mice with memory response) show \% survival. Data are combined from two independent experiments, $n=3-5$ mice per experiment. ${ }^{*} P<0.05,{ }^{* *} p<0.01,{ }^{* \star *} p<0.001$. 
A

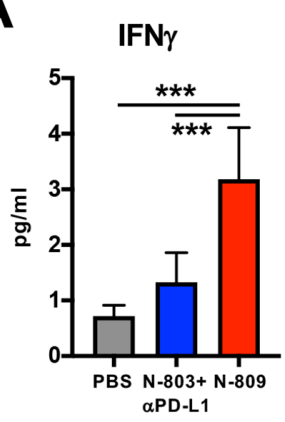

B

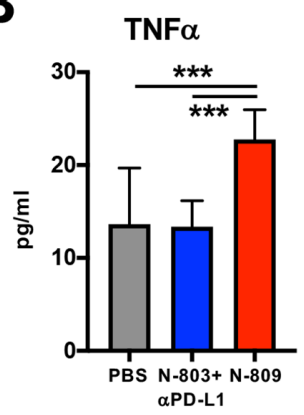

C

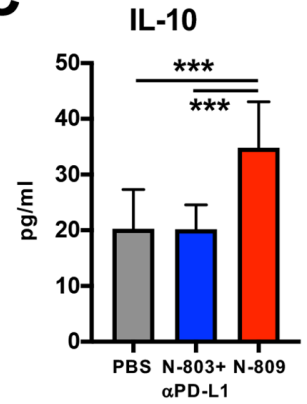

D

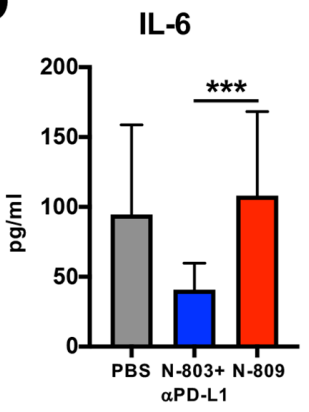

E

Interferon Signaling

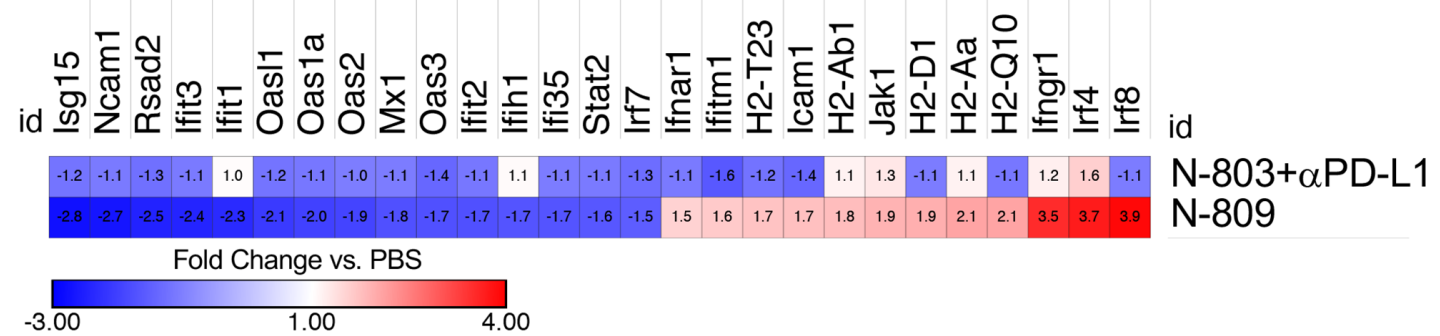

F

\section{Cytokine Signaling}

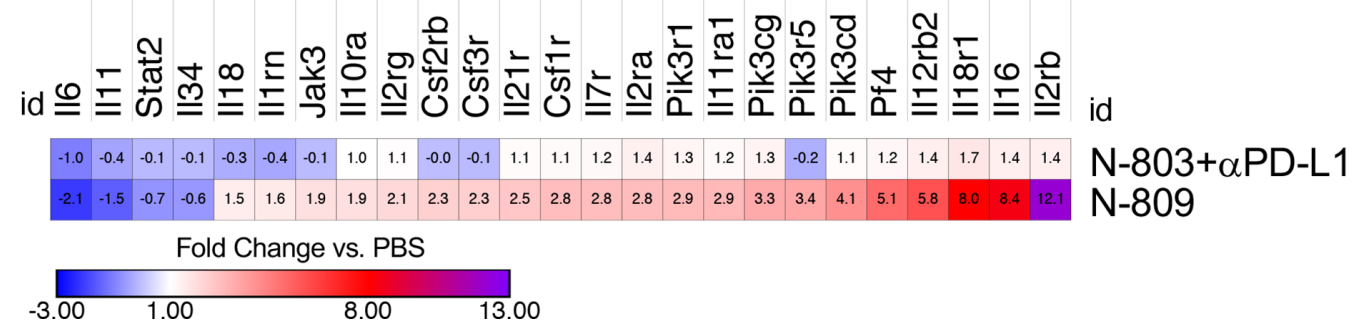

Figure $3 \quad \mathrm{~N}-809$ induces immunostimulatory cytokines in serum and increases cytokine signaling gene signatures in the tumor microenvironment (TME). MC38 tumors were implanted and mice treated as in figure 2. Primary tumor and serum were harvested 2 days after the last treatment. (A-D) Serum was analyzed for level of interferon (IFN) $\gamma(A)$, tumor necrosis factor (TNF) $\alpha(B)$, interleukin (IL)-10 (C) and IL-6 (D). All graphs show mean \pm SD. Data are combined from two to three independent experiments, $n=5$ mice/group per experiment. (E, F) RNA from the primary tumor was extracted and analyzed by NanoString. Heatmaps show fold change in gene expression related to IFN signaling (E) or cytokine signaling (F) over phosphate-buffered saline (PBS) (genes N-809 altered $>1.5$-fold). Data are from one experiment, $n=3-4$ mice/group. ${ }^{\star \star *} P<0.001$.

S3c). N-809 increased the ratio of immune effector to suppressive cells in the $\mathrm{dLN}$, as shown by enhanced $\mathrm{CD} 8^{+}$ $\mathrm{T}$ cell: $\mathrm{T}_{\text {reg }}$ (figure 4I) and M1-like:M2-like macrophage (figure $4 \mathrm{~N}$ ) ratios. N-803+ $\alpha$ PD-L1 treatment did not affect immune cell numbers in the dLN (figure $4 \mathrm{~F}-\mathrm{N}$ ). These data demonstrate that N-809, not N-803+oPD-L1, enhances the ratio of immune effector to suppressive cells within the TME and periphery.

\section{NK and $\mathrm{CD}^{+} \mathrm{T}$ cells are responsible for antitumor efficacy of N-809}

Given the increased number of $\mathrm{NK}$ and $\mathrm{CD} 8^{+} \mathrm{T}$ cells with N-809 treatment (figure 4F,G), we next performed depletion studies to determine whether these cell types were required for N-809 efficacy. Depletion of either $\mathrm{CD}^{+} \mathrm{T}$ cells (figure 5A) or NK cells (figure 5B) completely abrogated the antitumor efficacy of N-809 (figure 5C-E). Depletion of both $\mathrm{CD} 8^{+} \mathrm{T}$ cells and NK cells (figure $5 \mathrm{~A}, \mathrm{~B}$ ) did not further enhance this effect (figure $5 \mathrm{C}-\mathrm{E}$ ). Thus, $\mathrm{CD}^{+} \mathrm{T}$ cells and NK cells are required for the antitumor efficacy of N-809.

\section{$\mathrm{N}-809$ promotes NK cell activation in the TME and improves NK killing}

Next, we performed a comprehensive analysis of NK and $\mathrm{CD}^{+}$T-cell phenotype and function to further interrogate the mechanism of action of N-809. 


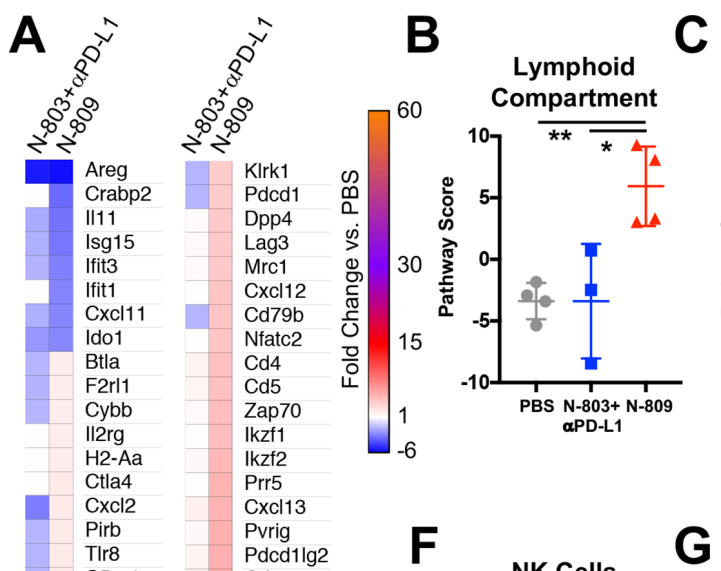

C5ar1 $\quad$ Cd6

Gata3 $\quad$ Cd200r

Cxcl3 Cd8a

Slamf7 Eomes

Ccl9

Csf3r

S100a9

TIr1

Ccl5

$\mathrm{Ccl} 8$

Cd48

Sirpa

Trem2

Csf1r

Nfam1

Prdm1

II2ra

Pik3r1

Ill1ra1

Cd38

Clec7a

Fpr1

Ptprc

Icos

Irf4

Ly9
Ccl6

$\mathrm{Ccl}$

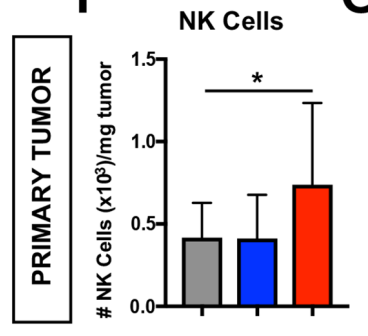

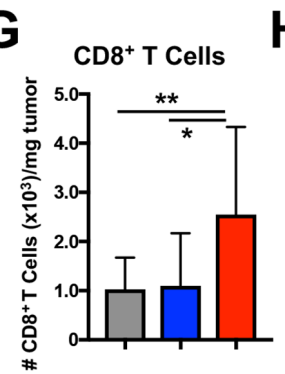

H

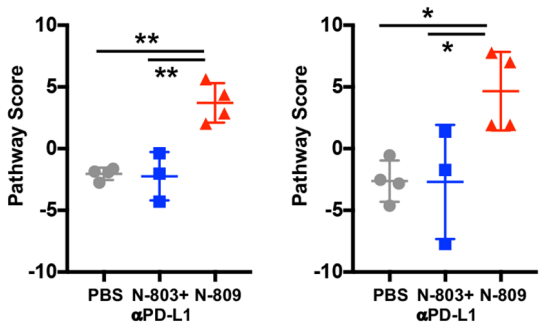

E

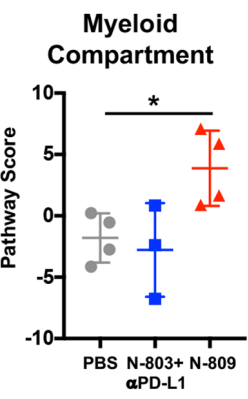

Figure 4 N-809 increases the ratio of immune effector to suppressive cells within the tumor microenvironment (TME) and periphery. MC38 tumors were implanted and mice treated as in figure 2. Primary tumor and draining lymph nodes (LN) were harvested 2 days after the last treatment. (A-E) RNA from the primary tumor was extracted and analyzed. (A) Heatmap of the genes from pathway scores for lymphoid compartment (B), cytotoxicity (C), costimulation (D) and myeloid compartment (E) that $\mathrm{N}-809$ altered more than two-fold. Data in heat map are represented as fold change in gene expression over phosphatebuffered saline (PBS). Data are from one experiment, $n=3-4$ mice/group. (F-N) The number of natural killer (NK) cells $(F)$, CD8 ${ }^{+} T$ cells $(G)$, regulatory $T$ cells $\left(T_{\text {reg }}\right)(H)$ and $C D 8^{+} T$ cell to $T_{\text {reg }}$ ratio $(I)$, or number of monocytic myeloid-derived suppressor cells (MMDSC) (J), total macrophages (K), M1-like macrophages (L), M2-like macrophages (M) and M1-like to M2-like macrophage ratio (N) were determined in the primary tumor (top) or draining LN (bottom) by flow cytometry. Data are combined from two to three independent experiments, $n=5$ mice/group per experiment. All graphs show mean $\pm S D$. ${ }^{*} P<0.05,{ }^{* *} p<0.01,{ }^{\star * *} p<0.001$. 
A

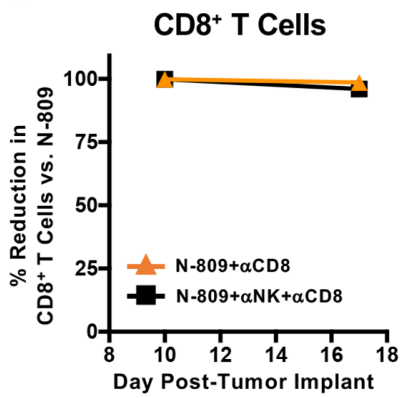

C

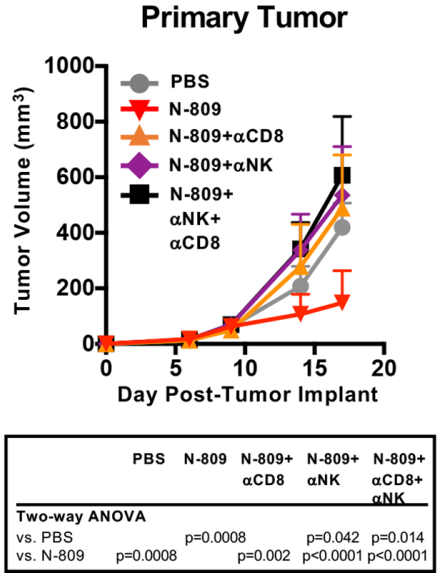

B

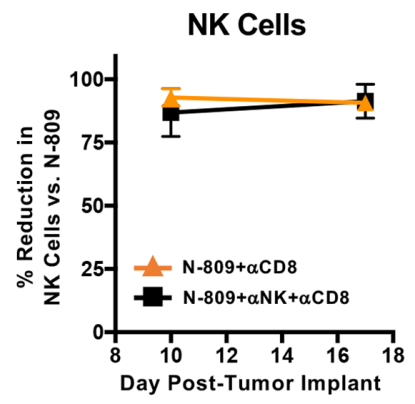

D

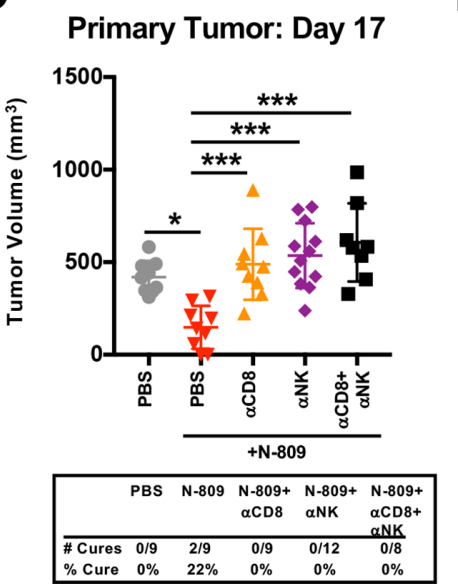

$\mathbf{E}$

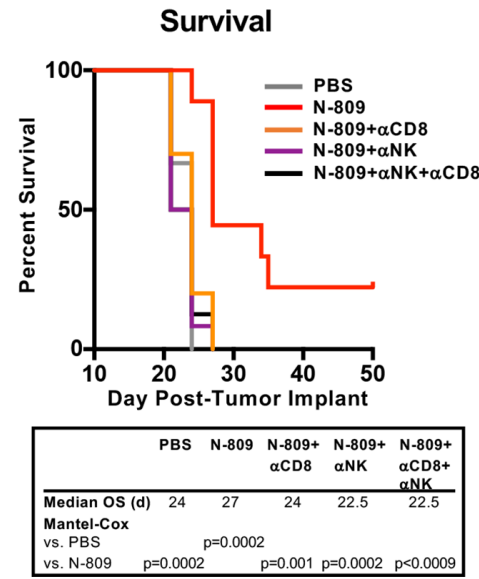

Figure $5 \mathrm{CD}^{+} \mathrm{T}$ cells and natural killer (NK) cells are required for the antitumor efficacy of N-809. MC38 tumors were implanted as in figure 1 and mice were treated at days 9 and 13 with $100 \mu \mathrm{g}-809$ (subcutaneously). CD8-expressing cells and NK cells were depleted on days 8,10,12,16 and 19 using $100 \mu \mathrm{g}$ anti-CD8 and/or $25 \mu \mathrm{L}$ anti-asialo-GM1 (intraperitoneally). (A, B) Blood was obtained on days 10 and 17 to determine efficiency of CD8 ${ }^{+}$T-cell (a) or NK cell (B) depletions. Graphs show mean \pm SD. (C, D) Primary tumor growth curves (inset: two-way analysis of variance (ANOVA)) (C) and tumor volumes of individual mice at day 17 (inset: \% cured mice) (D) show mean \pm SD. (E) Survival curves (inset: $\mathrm{mOS}$ ) show \% survival. Data are from one experiment, $n=8-12$ mice. ${ }^{*} \mathrm{P}<0.05,{ }^{\star \star \star} \mathrm{p}<0.001$.

In the TME, N-809 significantly increased NK cell expression of activation-induced NKG2D (figure 6A), proliferation-associated Ki67 (figure 6B) and cytolytic molecule granzyme B (figure 6C) versus PBS and N-803+ $\alpha$ PD-L1. Similar effects were observed in the dLN (figure 6A-C). In contrast to the TME, where N-803+ $\alpha$ PD-L1 did not affect NKG2D, Ki67 or granzyme B levels, the combination significantly enhanced NKG2D (figure 6A) and granzyme B (figure 6C) in the dLN, although less than $\mathrm{N}-809$ (figure $6 \mathrm{~A}-\mathrm{C}$ ). The function of NK cells markedly improved with $\mathrm{N}-809$ versus PBS or N-803+ $\alpha \mathrm{PD}-\mathrm{L} 1$, as shown by increased NK killing of Yac-1 target cells at all effector:target (E:T) ratios (figure $6 \mathrm{D}$ ). $\mathrm{N}-803+\alpha \mathrm{PD}-\mathrm{L} 1$ also enhanced NK cell killing, but it was significantly reduced versus N-809 (figure 6D). Similar effects on NK-mediated lysis were observed in 4T1 tumor-bearing mice (online supplementary figure S3d). Thus, N-809 promotes greater activation and function of NK cells than N-803+ $\alpha$ PD-L1.

\section{$\mathrm{N}-809$ induces $\mathrm{CDB}^{+} \mathrm{T}$-cell activation and enhances cytokine production in the TME}

Similar to the effect on NK cells, N-809 enhanced expression of Ki67 (figure 6E) and granzyme B (figure 6F) on activated intratumoral $\mathrm{CD} 8^{+} \mathrm{T}$ cells as compared with PBS and $\mathrm{N}-803+\alpha \mathrm{PD}-\mathrm{L} 1$. Additionally, central memory $\left(\mathrm{T}_{\mathrm{CM}}\right)$ (figure 6G), but not effector memory $\left(\mathrm{T}_{\mathrm{EM}}\right.$ ) (figure $6 \mathrm{H}$ ) or effector $\left(\mathrm{T}_{\text {eff }}\right)$ (figure $\left.6 \mathrm{I}\right) \mathrm{CD} 8^{+} \mathrm{T}$ cells, were expanded. N-809 did not affect CD8 ${ }^{+}$T-cell clonality in the tumor (online supplementary figure S3e,f). Similar to the TME, N-809 enhanced Ki67 (figure 6E) and granzyme $\mathrm{B}$ (figure 6F) expression on activated $\mathrm{CD} 8^{+} \mathrm{T}$ cells in the dLN. In contrast to the tumor, N-809 increased the proportion of $\mathrm{T}_{\mathrm{CM}}$ (figure $6 \mathrm{G}$ ), $\mathrm{T}_{\mathrm{EM}}$ (figure $6 \mathrm{H}$ ) and $\mathrm{T}_{\text {eff }}$ (figure $6 \mathrm{I}) \mathrm{CD}^{+} \mathrm{T}$ cells. N-803+ $\mathrm{\alpha PD}-\mathrm{L} 1$ did not significantly alter $\mathrm{CD} 8^{+}$T-cell phenotype in the tumor or dLN (figure 6E-I).

Correlating with the development of a more active CD8 ${ }^{+}$ T-cell phenotype, N-809 increased the proportion of activated $\mathrm{CD}^{+} \mathrm{T}$ cells in the TME and $\mathrm{dLN}$ that produced IFN $\gamma$ (figure 6J), TNF $\alpha$ (figure 6K) and both IFN $\gamma$ and $\mathrm{TNF} \alpha$ (figure $6 \mathrm{~L}$ ) versus PBS and $\mathrm{N}-803+\alpha \mathrm{PD}-\mathrm{L} 1$. IFN $\gamma$ production in the tumor did not change with treatment (online supplementary figure $\mathrm{S3g}$ ), but N-809 significantly increased $\mathrm{TNF} \alpha$ production on a per cell basis in the dLN (online supplementary figure S3h). N-803+ $\mathrm{PDD}-\mathrm{L} 1$ 
A NKG2D B $\quad$ Ki67 $\quad$ C $\quad$ Granzyme B
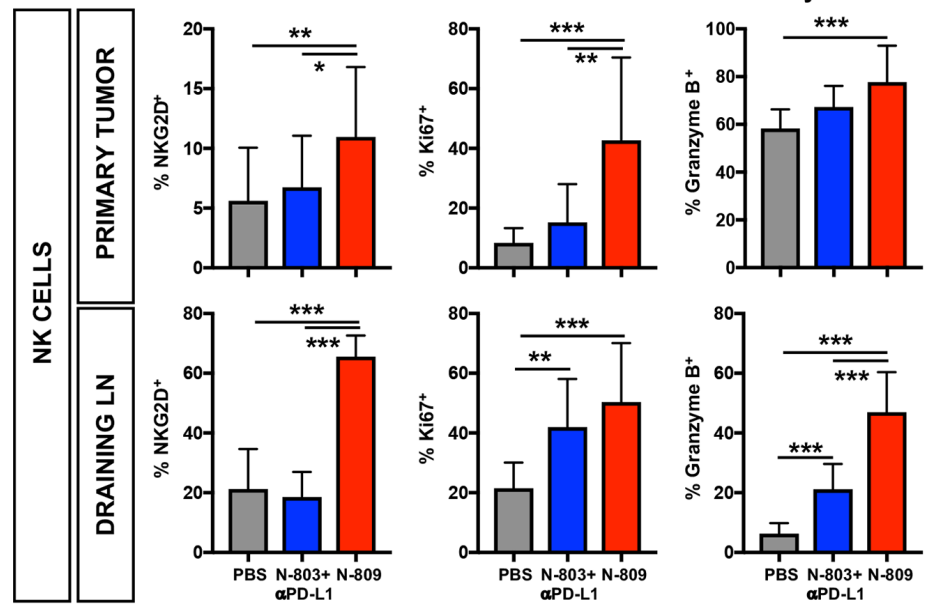

E

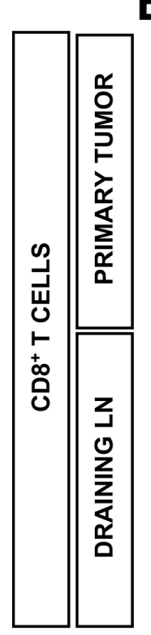

$\mathbf{F}$

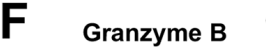

G

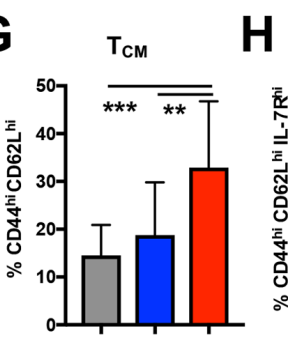

$T_{E M}$

D NK Killing
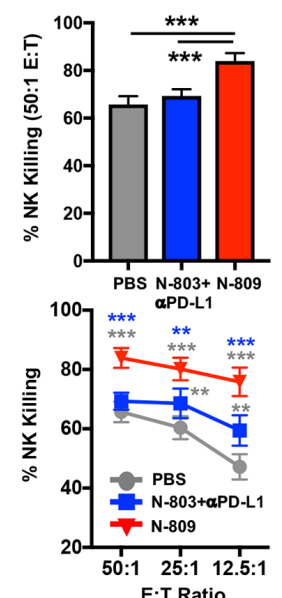

E:T Ratio Ki67
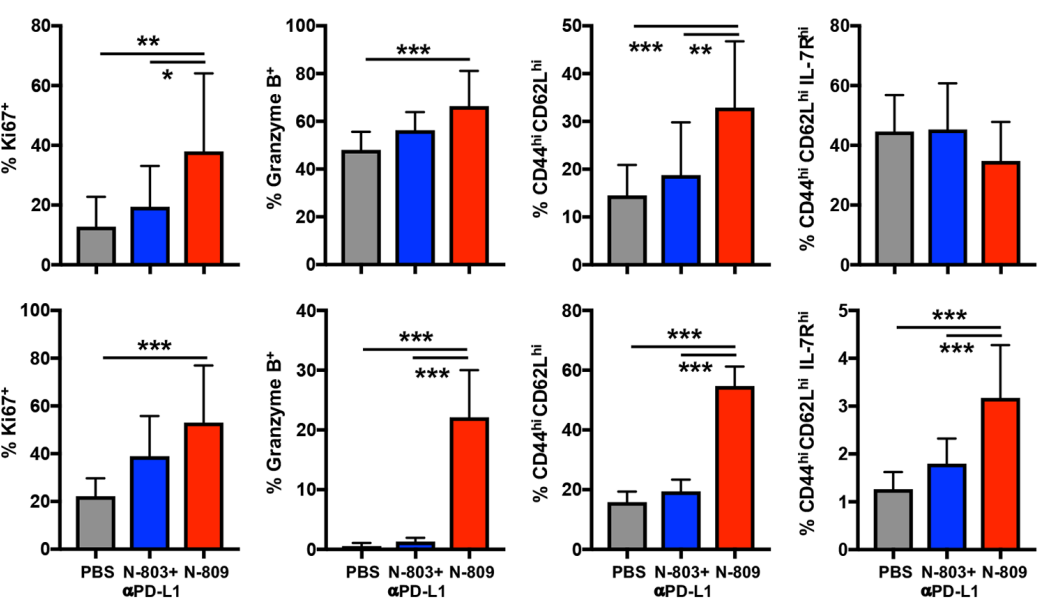
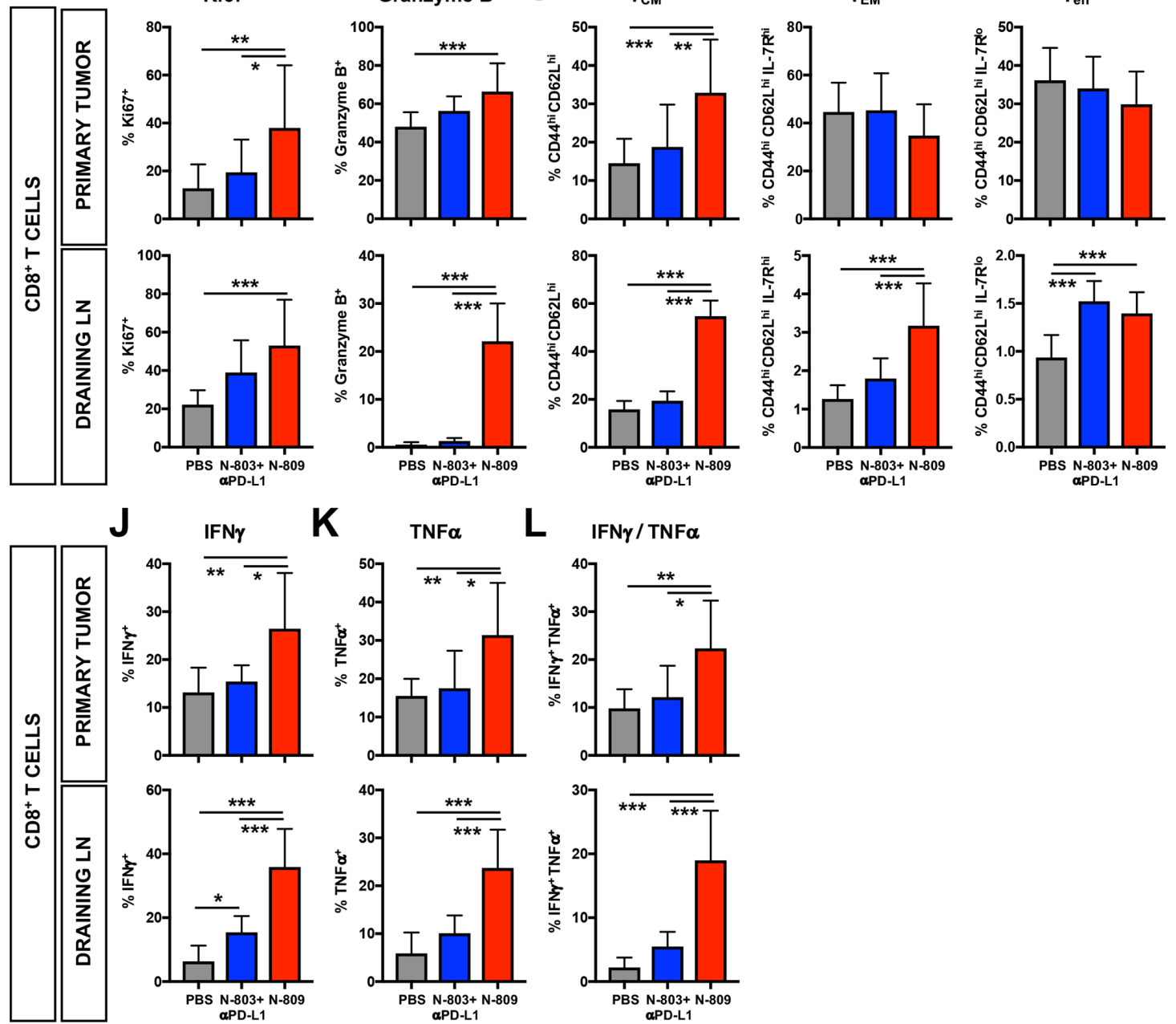

\section{IFN / TNF $\alpha$}
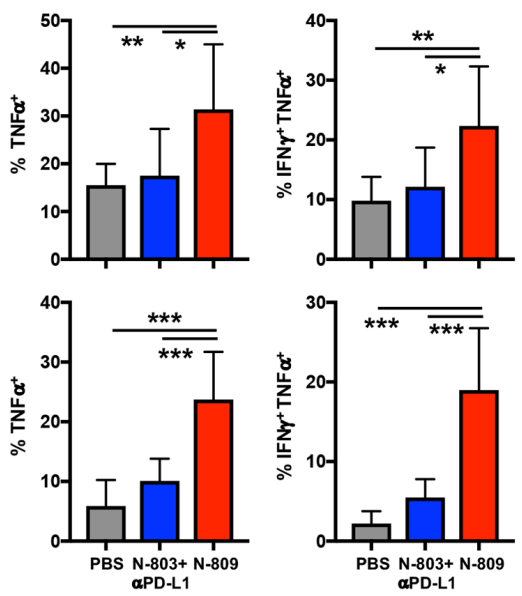

Figure $6 \quad \mathrm{~N}-809$ induces an activated natural killer (NK) and CD8 ${ }^{+}$T-cell phenotype and enhances function. MC38 tumors were implanted and mice treated as in figure 2. NK (A-D) and CD8 ${ }^{+} T$ cells $(E-l)$ were examined by flow cytometry. (A-C) Graphs show frequency of $\mathrm{NKG} \mathrm{D}^{+}(\mathrm{A}), \mathrm{Ki} \mathrm{7}^{+}(\mathrm{B})$ and granzyme $\mathrm{B}^{+}(\mathrm{C}) \mathrm{NK}$ cells in the primary tumor (top) and draining lymph nodes (LN) (bottom). (D) Purified splenic NK cells were co-cultured with ${ }^{111}$ In-labeled Yac-1 target cells at the designated E:T ratios for 18 hours. ${ }^{111}$ In release was measured to determine cytotoxic function. (E-I) Graphs show frequency of CD44 $4^{\text {hi }} \mathrm{Ki} 67^{+}(\mathrm{E})$,

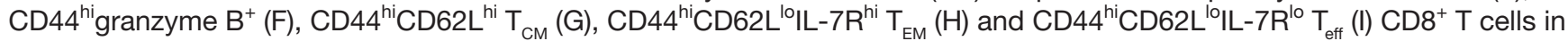
the primary tumor (top) and draining $\mathrm{LN}$ (bottom). (J-L) Immune cells were stimulated with $1 \mu \mathrm{g} / \mathrm{mL} \alpha \mathrm{CD} 3+1 \mu \mathrm{g} / \mathrm{mL} \alpha \mathrm{CD} 28$ for 4 hours. Graphs show frequency of total interferon (IFN) $\gamma^{+}(J)$, total tumor necrosis factor (TNF) $\alpha^{+}(\mathrm{K})$ and IFN $\gamma / T N F \alpha$-double producing (L) CD44 ${ }^{\text {hi }} \mathrm{CD} 8^{+} \mathrm{T}$ cells in the primary tumor (top) and draining $\mathrm{LN}$ (bottom) as determined by flow cytometry. All graphs show mean $\pm S D$. Data combined from two to three independent experiments, $n=5$ mice/group per experiment. ${ }^{*} P<0.05$, ${ }^{\star \star} p<0.01,{ }^{* \star *} p<0.001$. 
only increased the proportion of $\mathrm{CD} 8^{+} \mathrm{T}$ cells producing IFN $\gamma$ in the dLN, but not to the level induced by N-809 (figure 6J). N-809, but not N-803+ $\alpha$ PD-L1, also enhanced $\mathrm{CD}^{+} \mathrm{T}$-cell function in the lungs of $4 \mathrm{~T} 1$ tumor-bearing mice, as shown by the increased proportion of IFN $\gamma$-producing (online supplementary figure S3i), TNFoproducing (online supplementary figure S3j) and IFN $\gamma$ / TNFo-producing (online supplementary figure S3k) $\mathrm{CD}^{+} \mathrm{T}$ cells. Together, these data suggest that N-809 induces activation and increases function of $\mathrm{CD}^{+} \mathrm{T}$ cells greater than N-803+ $\alpha$ PD-L1.

\section{$\mathrm{N}-809$ drives $\mathrm{CD}^{+}{ }^{+} \mathrm{T}$-cell and NK cell migration into the TME through regulation of chemokine levels and chemokine receptor expression}

$\mathrm{N}-809$ promotes the accumulation of a large number of active, functional $\mathrm{CD}^{+} \mathrm{T}$ cells and NK cells within the TME (figures 4F,G and 5). This occurs through proliferation within the tumor or migration of de novo $\mathrm{CD} 8^{+}$ $\mathrm{T}$ cells and NK cells from the periphery. In order to distinguish between these possibilities, we administered FTY720 to mice treated with N-809. FTY720 is a sphingosine-1 phosphate receptor inhibitor that sequesters lymphocytes within secondary lymphoid organs and prevents migration in the blood. ${ }^{28} \mathrm{CD} 8^{+} \mathrm{T}$ cells are more sensitive to FTY720 than NK cells, ${ }^{29}{ }^{30}$ as demonstrated by a significant reduction in $\mathrm{CD}^{+} \mathrm{T}$ cells (figure $7 \mathrm{~B}$ ), but not NK cells (figure 7A), in the blood after FTY720 treatment. Thus, only $\mathrm{CD} 8^{+} \mathrm{T}$-cell expansion versus migration could be evaluated. N-809-induced increase of $\mathrm{CD} 8^{+}$ T-cell number in the TME was completely abrogated by FTY720 administration (figure 7C), suggesting that N-809 promotes lymphocyte trafficking of $\mathrm{CD} 8^{+} \mathrm{T}$ cells into the tumor, not in situ expansion.

To investigate the effect of $\mathrm{N}-809$ on $\mathrm{CD}^{+}$T-cell and NK cell trafficking, intratumoral gene expression associated with chemokine signaling was evaluated by NanoString. N-809 had a greater overall effect on genes related to chemokine signaling than $N-803+\alpha$ PD-L1 (figure 7D). N-809 significantly enhanced the expression of genes associated with migration of $\mathrm{CD}^{+} \mathrm{T}$ cells and NK cells, including Cxcr3 (CXCR3), Ccr5 (CCR5) and Ccl5 (CCL5), with Cxcr3 being the most upregulated gene in the TME (figure 7D).

To confirm these findings, we determined chemokine levels in the TME and chemokine receptor expression on NK and $\mathrm{CD} 8^{+} \mathrm{T}$ cells. Particular focus was placed on NK and $\mathrm{CD}^{+}$T-cell-expressed chemokine receptors CXCR3 and CCR5 and their respective ligands CXCL9/10 and CCL4/5, as they are the main drivers of NK and CD8 ${ }^{+}$ T-cell migration to inflamed tissues and tumors. ${ }^{31-33}$ In the TME, N-809 significantly increased the level of CXCR3 ligand CXCL9 (figure 7E) but not CXCL10 (figure 7F). $\mathrm{N}-809$ also increased CCR5 ligands CCL4 (figure 7G) and CCL5 (figure 7H). N-809 greatly upregulated expression of CXCR3 and CCR5 on NK (figure 7I,J) and CD8 ${ }^{+} \mathrm{T}$ cells (figure 7K,L) in the dLN and spleen. There was no expression of CXCR3 or CCR5 on NK or $\mathrm{CD}^{+} \mathrm{T}$ cells in the tumor (online supplementary figure S4). Correlating with its inability to increase immune cell numbers in the tumor, N-803+ $\alpha$ PD-L1 did not affect chemokine levels in the TME (figure 7E-H) or chemokine receptor expression on $\mathrm{NK}$ or $\mathrm{CD}^{+} \mathrm{T}$ cells (figure $7 \mathrm{I}-\mathrm{L}$ ). These data suggest that $\mathrm{N}-809$ increases effector cell numbers in the tumor through chemokine-induced $\mathrm{CD} 8^{+} \mathrm{T}$-cell and NK cell trafficking to the TME.

\section{DISCUSSION}

$\alpha \mathrm{PD}-1 / \mathrm{PD}-\mathrm{L} 1$ therapies can reduce immunosuppression within the TME by blocking the $\alpha \mathrm{PD}-1 / \alpha \mathrm{PD}-\mathrm{L} 1$ interaction of $\mathrm{T}$ cells and tumor or immunosuppressive cell types. ${ }^{6}$ These therapies can also skew immunosuppressive cells like macrophages toward a more inflammatory, antitumor phenotype to support tumor rejection. ${ }^{4}$ The effect of $\alpha$ PD-1/PD-L1 therapies on effector cell populations has recently undergone a paradigm shift with the demonstration that they do not primarily mediate their efficacy through reinvigoration of $\mathrm{T}$ cells in the TME. Instead, migration of novel, peripherally activated $\mathrm{CD} 8^{+}$ T-cell clones is required for improved antitumor efficacy. $^{235}$ Together, these observations suggest that immunotherapy strategies that reduce immunosuppressive cell populations, promote systemic T-cell responses and mediate lymphocyte trafficking to the TME may surpass the limited clinical efficacy of $\alpha$ PD-1/PD-L1 monotherapy in patients with carcinoma.

Bispecific/bifunctional immunotherapeutic agents simultaneously interact with two targets, allowing for specific localization of the agent, increased local effects, reduced toxicity and/or dual effects on distinct biological mechanisms. ${ }^{17-19}$ Thus, bifunctional immunotherapeutics may improve clinical outcome for patients with carcinoma using a single agent versus multiagent combination therapy strategies. In the studies presented here, we evaluated N-809, a novel bifunctional molecule composed of the IL-15/IL-15R $\alpha$ superagonist N-803 fused to antiPD-L1 domains. ${ }^{21}$ IL-15/IL-15R $\alpha$ complexes have been fused with antibody domains before. ${ }^{34-36}$ To our knowledge, $\mathrm{N}-809$ is the first bifunctional agent that pairs an IL-15/IL-15R $\alpha$ complex and a checkpoint inhibitor and thus the potential to provide immune-activating signals while preventing suppression.

$\mathrm{N}-809$ was administered subcutaneously, as N-803 is better tolerated when given subcutaneously versus intravenously. ${ }^{14} 1526$ Recent studies demonstrated that subcutaneous administration of antibodies, including $\alpha \mathrm{PD}-\mathrm{L} 1$, does not reduce efficacy and may improve tolerability versus intravenous delivery. ${ }^{37} 38$ N-809 was welltolerated when given subcutaneously, with no visible toxicity or loss of body weight. The observed transient, non-lethal, dose-dependent increase in inflammation in multiple organs correlated with an increased level of serum IFN $\gamma$, a known driver of IL-15 superagonistmediated toxicity. ${ }^{26} 3940$ Increasing the interval between $\mathrm{N}-809$ doses, similar to the once per week clinical N-803 
A

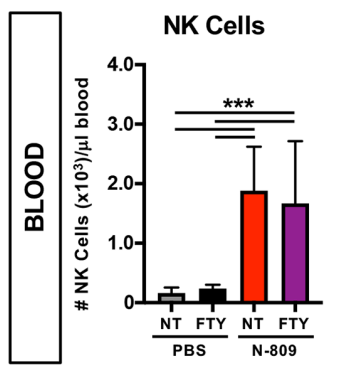

D
B

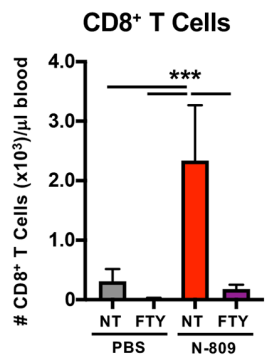

C

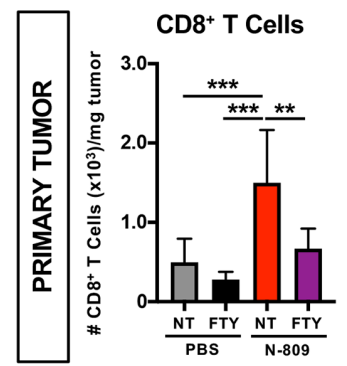

\section{Chemokine Signaling}
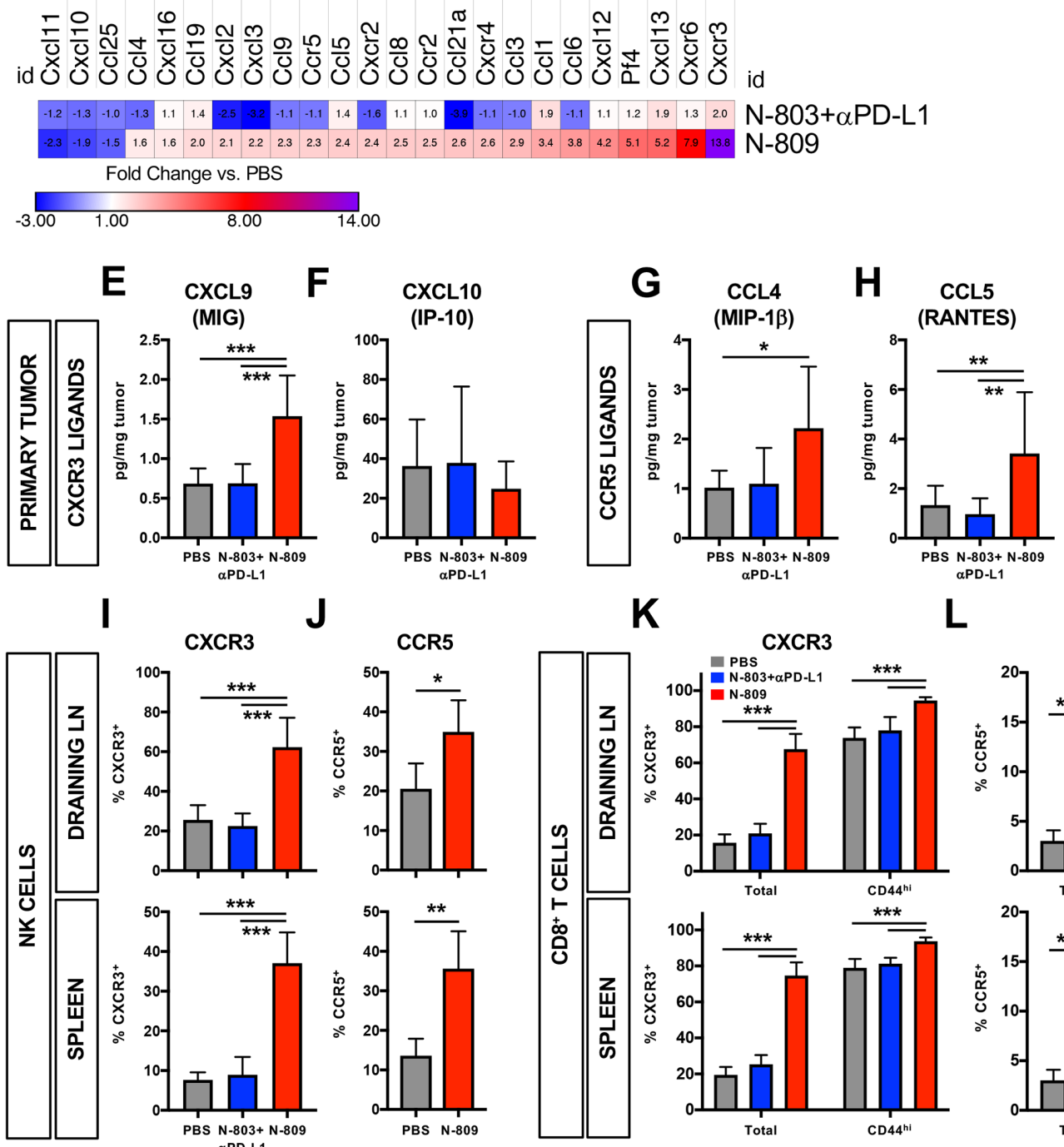

$\mathbf{L}$

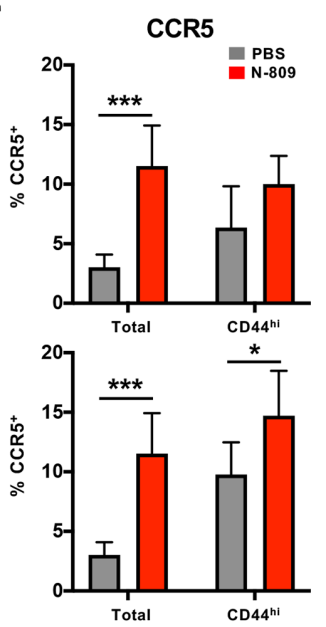

Figure 7 N-809 increases chemokine levels and chemokine receptors related to CD8 ${ }^{+}$T-cell and natural killer (NK) cell migration. (A-C) MC38 tumors were implanted as in figure 1 and mice were gavaged daily beginning at day 9 with $25 \mu \mathrm{g}$ FTY720. At days 10 and 14, mice were treated with $100 \mu \mathrm{g} \mathrm{N}-809$ (subcutaneously). Immune cells were examined by flow cytometry. Graphs show numbers of NK cells $(A)$ or $C D 8^{+}$T cells in the blood (B) or in the primary tumor (C). Data are combined from two independent experiments, $n=5-6$ mice per group. (D-L) MC38 tumors were implanted and mice treated as in figure 2. All analysis was performed 2 days after the last treatment. (D) RNA from the primary tumor was extracted and analyzed by NanoString. Heatmaps show fold change in gene expression related to chemokine signaling over phosphate-buffered saline (PBS) (genes N-809 altered >1.5-fold). Data are from one experiment, $\mathrm{n}=3-4$ mice/group. (E-H) Graphs show intratumoral concentrations of CXCR3 ligands CXCL9 (E) and CXCL10 (F) and CCR5 ligands CCL4 (G) and CCL5 (H). Data are combined from two to three independent experiments, $n=5$ mice/group per experiment. (I-L) NK cells (l, J) and CD8 ${ }^{+} T$ cells $(K, L)$ were examined by flow cytometry in the draining lymph nodes (LN) (top) and spleen (bottom). Graphs show CXCR3 ${ }^{+}$(I) or CCR5 ${ }^{+}$ (J) NK cells and $\mathrm{CXCR3}^{+}(\mathrm{K})$ or $\mathrm{CCR}^{+}(\mathrm{L})$ total or CD44 ${ }^{\mathrm{hi}} \mathrm{CD}^{+} \mathrm{T}$ cells. Data are combined from one to two independent experiments, $n=5$ mice/group per experiment. All graphs show mean $\pm S D$. ${ }^{\star} P<0.05,{ }^{* *} p<0.01,{ }^{* * *} p<0.001$. 
dosing, ${ }^{15}$ may ameliorate these effects. In contrast to $\mathrm{N}-809$, N-803 is extremely toxic at high doses, so we were unable to evaluate equimolar doses of N-809 and N-803+ $\alpha$ PD-L1. Thus, we compared N-809 with the clinically relevant dose of N-803+ $\alpha$ PD-L1, ${ }^{9} 1415$ a dose not previously evaluated in murine models. ${ }^{16}$ This difference in tolerability may be attributed to the reduction in IL-15 activity of $\mathrm{N}-809$ versus $\mathrm{N}-803$. However, it also suggests that PD-L1-targeting of an IL-15 superagonist reduces toxicity, as previously described. ${ }^{41}{ }^{42}$ Extrapolating our findings, it may be possible that the clinically tolerated dose of N-809 is higher than N-803, leading to increased efficacy of N-809 in patients. The studies described here provide the rationale for such clinical investigation.

$\mathrm{N}-809$ was superior to N-803+oPD-L1 in reducing 4T1 and MC38 tumor burden and increasing survival of MC38 tumor-bearing mice. The greater antitumor efficacy of $\mathrm{N}-809$ versus $\mathrm{N}-803+\alpha \mathrm{PD}-\mathrm{L} 1$ was unexpected, especially since N-809 had reduced PD-L1 occupancy in the tumor and peripheral immune compartment. This suggests that the $\mathrm{N}-803$ component is the main driver of $\mathrm{N}-809$ antitumor efficacy. Less PD-L1 blockade by N-809 versus $\mathrm{N}-803+\alpha \mathrm{PD}-\mathrm{L} 1$ was most likely due to the reduced relative dose of $\alpha$ PD-L1 antibody administered $(100 \mu \mathrm{g}$ N-809 vs $200 \mu \mathrm{g} \alpha \mathrm{PD}-\mathrm{L} 1)$. Additionally, it could be attributed to an increase in global PD-L1 expression by the IL-15 superagonist component since $\mathrm{N}-803$ is known to upregulate PD-L1 expression. ${ }^{16}$ Thus, one can speculate that the superior antitumor efficacy of N-809 may arise from increased retention of its IL-15/IL-15R $\alpha$ in the TME, brought by the binding to PD-L1.

The improved efficacy of $\mathrm{N}-809$ correlated with an inflamed gene expression signature in the TME characterized by increased costimulation, cytotoxicity and IFN and proinflammatory cytokine signaling. N-809 enhanced the number of activated $\mathrm{NK}$ and $\mathrm{CD} 8^{+} \mathrm{T}$ cells in the periphery and tumor, and significantly increased NK and $\mathrm{CD} 8^{+}$T-cell function. These results support the hypothesis that N-809 enhances intratumoral lymphocyte numbers by increasing trafficking via altered chemokine levels in the TME and chemokine receptor expression on $\mathrm{CD}^{+} \mathrm{T}$ cells and NK cells. In addition, chemical inhibition of T-cell migration reduced intratumoral $\mathrm{CD} 8^{+} \mathrm{T}$-cell numbers after N-809 treatment. Moreover, N-809 greatly upregulated the chemokine receptors CXCR3 and CCR5 on peripheral $\mathrm{CD}^{+} \mathrm{T}$ cells and NK cells, which are important for efficient T-cell and NK cell tumor infiltration. ${ }^{31-33}$ CXCR3 and CCR5 ligands CXCL9, CCL4 and CCL5, but not other chemokines, were also increased in the TME. N-803+oPD-L1 did not alter chemokine receptor expression or chemokine levels, suggesting that the mechanism of action of N-809 may be unique. While IL-15 has been shown to promote transient, peripheral retention of immune cells, ${ }^{43}$ the effect of IL-15 immunotherapy on immune cell trafficking in cancer has not been described. Our results showing that the increase in $\mathrm{CD}^{+}$ T-cell number in the TME was due to migration, not in situ expansion, mirrors a recent clinical study demonstrating that the enhanced number of intratumoral $\mathrm{CD}^{+} \mathrm{T}$ cells observed after $\alpha \mathrm{PD}-1$ therapy was due to the migration of de novo activated peripheral T cells. ${ }^{5}$ Additional studies have described similar results with $\alpha$ PD-L1 therapy in preclinical models. $^{23}$

Given the clinical and preclinical studies with $\mathrm{N}-803+\alpha \mathrm{PD}-1 / \mathrm{PD}-\mathrm{L} 1$ combination, it was expected for $\mathrm{N}-809$ to increase the number of $\mathrm{CD} 8^{+} \mathrm{T}$ cells and NK cells. ${ }^{15162444}$ However, in contrast to previous studies with $\mathrm{N}-803+\alpha \mathrm{PD}-\mathrm{L} 1,{ }^{16} \mathrm{~N}-809$ treatment significantly reduced immunosuppressive and pro-tumorigenic immune cells in the TME, including $\mathrm{T}_{\text {reg }}$, M2-like macrophages and M-MDSC. Given the pro-inflammatory cytokine signature in the TME and serum, the decrease in $\mathrm{T}_{\text {reg }}$ and M2-like macrophages could be due to reprogramming of these cells. $\alpha$ PD-L1 therapy has been shown to skew M2-like to M1-like macrophages. ${ }^{4}$ However, the number of non-T ${ }_{\text {reg }}$ $\mathrm{CD} 4^{+} \mathrm{T}$ cells and M1-like macrophages did not concomitantly increase with the reduction of $\mathrm{T}_{\text {reg }}$ and M2-like macrophages, suggesting that these suppressive cells underwent apoptosis or cell-mediated death. $\mathrm{T}_{\text {reg }}$ versus conventional $\mathrm{CD} 4^{+} \mathrm{T}$ cells undergo increased apoptosis in the TME due to oxidative stress, ${ }^{45}$ and high levels of IFN $\gamma$ can induce cell death by other mechanisms. Alternatively, N-809 can mediate antibody-dependent cellular cytotoxicity (ADCC) of PD-L1-expressing tumor targets by NK cells. ${ }^{21} \mathrm{~N}-809$ enhanced NK cell activation and function, and PD-L1 expression increased on macrophages and M-MDSC upon IL-15 superagonist treatment. Thus, it is possible that PD-L1-expressing M2-like macrophages and M-MDSC underwent NK cell-mediated ADCC after N-809 treatment. While PD-L1 expression on macrophages prevents killing by effector cells, ${ }^{46}$ the lower level of MHC class I on M2 versus M1 macrophages may increase their susceptibility to NK-mediated killing. ${ }^{47}$ The exact effect of N-809 on immunosuppressive cell populations in the TME is currently under investigation. Regardless, the reduction in intratumoral $\mathrm{T}_{\text {reg }}$, M2-like macrophages and M-MDSC could support N-809 efficacy, as the presence of these cell populations is associated with worse effector responses and prognosis. ${ }^{48-50}$

\section{CONCLUSIONS}

For the first time, we demonstrate that a bifunctional molecule targeting PD-L1 and IL-15 induces significant tumor control in multiple murine carcinoma models resistant to N-803 or $\alpha$ PD-L1 monotherapy. N-809 functions by increasing intratumoral $\mathrm{NK}$ and $\mathrm{CD}^{+} \mathrm{T}$ cells, most likely through migration of peripherally activated cells into the TME, not in situ proliferation. The antitumor efficacy of N-809 was further associated with significant reduction in tumor $\mathrm{T}_{\mathrm{reg}}$ and M2-like macrophages. Notably, this antitumor efficacy and novel immune mechanism was not observed with $\mathrm{N}-803+\alpha \mathrm{PD}-\mathrm{L} 1$, an immunotherapy combination in the clinic. Overall, we conclude that N-809 reduces tumor burden by inducing the development of an inflamed TME through reduction 
of immunosuppressive cell populations and altered trafficking of activated effector immune cells. This is of particular importance as non-inflamed tumors are unlikely to respond to immune checkpoint inhibitors alone or in combination. Thus, agents such as N-809 represent an unmet medical need for converting 'cold' tumors to inflamed ones. These results provide the rationale for the clinical use of $\mathrm{N}-809$ for treatment of carcinomas, including for patients with cold tumors, or an innate or acquired resistance to $\alpha$ PD-L1 therapy.

Acknowledgements The authors would like to thank Curtis Randolph for excellent technical assistance; Yanyu Wang, Sara Loftus and Ludmila Krymskaya (Clinical Support Laboratory, Frederick National Laboratory for Cancer Research, Leidos Biomedical Research) for their technical support; and Debra Weingarten for her assistance in the preparation of this manuscript.

Contributors Designing of research studies: KMK, SG and JS. Conducting experiments: KMK, KCH, YO, SG. Acquiring data: KMK, KCH. Analyzing data: KMK, KCH, SG. Writing the manuscript: KMK, SG and JS. All authors read and approved the final manuscript.

Funding This research was supported by the Intramural Research Program of the Center for Cancer Research, National Cancer Institute (NCI), National Institutes of Health, and by a Cooperative Research and Development Agreement (CRADA) between the $\mathrm{NCl}$ and ImmunityBio.

Disclaimer The authors from the National Cancer Institute do not have any competing interests to disclose.

Competing interests None declared.

\section{Patient consent for publication Not required.}

Ethics approval All in vivo experiments were approved by the NIH Intramural Animal Care and Use Committee (IACUC).

Provenance and peer review Not commissioned; externally peer reviewed.

Data availability statement Data are available on reasonable request. The data generated and analyzed will be made available from the corresponding author on reasonable request.

Open access This is an open access article distributed in accordance with the Creative Commons Attribution Non Commercial (CC BY-NC 4.0) license, which permits others to distribute, remix, adapt, build upon this work non-commercially, and license their derivative works on different terms, provided the original work is properly cited, appropriate credit is given, any changes made indicated, and the use is non-commercial. See http://creativecommons.org/licenses/by-nc/4.0/.

\section{ORCID iDs}

Jeffrey Schlom http://orcid.org/0000-0001-7932-4072

Sofia R Gameiro http://orcid.org/0000-0002-2392-8122

\section{REFERENCES}

1 Smyth MJ, Ngiow SF, Ribas A, et al. Combination cancer immunotherapies tailored to the tumour microenvironment. Nat Rev Clin Oncol 2016:13:143-58.

2 Fransen MF, Schoonderwoerd M, Knopf P, et al. Tumor-draining lymph nodes are pivotal in PD-1/PD-L1 checkpoint therapy. JCI Insight 2018;3. doi:10.1172/jci.insight.124507. [Epub ahead of print: 06 Dec 2018].

3 Spitzer MH, Carmi Y, Reticker-Flynn NE, et al. Systemic immunity is required for effective cancer immunotherapy. Cell 2017;168:e15:487-502.

4 Xiong H, Mittman S, Rodriguez R, et al. Anti-Pd-L1 treatment results in functional remodeling of the macrophage compartment. Cancer Res 2019;79:1493-506.

5 Yost KE, Satpathy AT, Wells DK, et al. Clonal replacement of tumorspecific T cells following PD-1 blockade. Nat Med 2019;25:1251-9.

6 Zou W, Wolchok JD, Chen L. Pd-L1 (B7-H1) and PD-1 pathway blockade for cancer therapy: mechanisms, response biomarkers, and combinations. Sci Transl Med 2016;8:328rv4.

7 Robert C, Schachter J, Long GV, et al. Pembrolizumab versus ipilimumab in advanced melanoma. N Engl J Med 2015;372:2521-32.
8 Carbone DP, Reck M, Paz-Ares L, et al. First-Line nivolumab in stage IV or recurrent non-small-cell lung cancer. N Engl J Med 2017;376:2415-26.

9 Apolo AB, Infante JR, Balmanoukian A, et al. Avelumab, an antiprogrammed death-ligand 1 antibody, in patients with refractory metastatic urothelial carcinoma: results from a multicenter, phase lb study. J Clin Oncol 2017;35:2117-24.

10 Waldmann TA. Cytokines in cancer immunotherapy. Cold Spring Harb Perspect Biol 2018;10. doi:10.1101/cshperspect.a028472. [Epub ahead of print: 03 Dec 2018].

11 Conlon KC, Lugli E, Welles HC, et al. Redistribution, hyperproliferation, activation of natural killer cells and CD8 T cells, and cytokine production during first-in-human clinical trial of recombinant human interleukin-15 in patients with cancer. J Clin Oncol 2015;33:74-82.

12 Miller JS, Morishima C, McNeel DG, et al. A first-in-human phase I study of subcutaneous outpatient recombinant human IL15 (rhIL15) in adults with advanced solid tumors. Clin Cancer Res 2018;24:1525-35.

13 Rhode PR, Egan JO, Xu W, et al. Comparison of the superagonist complex, ALT-803, to IL15 as cancer immunotherapeutics in animal models. Cancer Immunol Res 2016;4:49-60.

14 Margolin K, Morishima C, Velcheti V, et al. Phase I trial of ALT-803, a novel recombinant IL15 complex, in patients with advanced solid tumors. Clin Cancer Res 2018;24:5552-61.

15 Wrangle JM, Velcheti V, Patel MR, et al. ALT-803, an IL-15 superagonist, in combination with nivolumab in patients with metastatic non-small cell lung cancer: a non-randomised, openlabel, phase 1B trial. Lancet Oncol 2018;19:694-704.

16 Knudson KM, Hicks KC, Alter S, et al. Mechanisms involved in IL-15 superagonist enhancement of anti-PD-L1 therapy. J Immunother Cancer 2019;7:82

17 Huehls AM, Coupet TA, Sentman CL. Bispecific T-cell engagers for cancer immunotherapy. Immunol Cell Biol 2015;93:290-6.

18 Dougan M, Dougan SK. Targeting immunotherapy to the tumor microenvironment. J Cell Biochem 2017;118:3049-54.

19 Marshall HT, Djamgoz MBA. Immuno-Oncology: emerging targets and combination therapies. Front Oncol 2018;8:315.

20 Lan Y, Zhang D, Xu C, et al. Enhanced preclinical antitumor activity of M7824, a bifunctional fusion protein simultaneously targeting PD-L1 and TGF- $\beta$. Sci Transl Med 2018;10:eaan5488.

21 Jochems C, Tritsch SR, Knudson KM, et al. The multi-functionality of $\mathrm{N}-809$, a novel fusion protein encompassing anti-PD-L1 and the IL-15 superagonist fusion complex. Oncoimmunology 2019;8:e1532764.

22 Fox BA, Spiess PJ, Kasid A, et al. In vitro and in vivo antitumor properties of a T-cell clone generated from murine tumor-infiltrating lymphocytes. J Biol Response Mod 1990;9:499-511.

23 Pulaski BA, Ostrand-Rosenberg S. Mouse 4T1 breast tumor model. Curr Protoc Immunol 2001; Chapter 20:Unit 20.2

24 Kim PS, Kwilas AR, Xu W, et al. II-15 superagonist/IL-15R $\alpha$ SushiFc fusion complex (IL-15SA/IL-15RoSu-Fc; ALT-803) markedly enhances specific subpopulations of NK and memory CD8+ T cells, and mediates potent anti-tumor activity against murine breast and colon carcinomas. Oncotarget 2016;7:16130-45.

25 Boyman O, Krieg C, Homann D, et al. Homeostatic maintenance of $\mathrm{T}$ cells and natural killer cells. Cell Mol Life Sci 2012;69:1597-608.

26 Romee R, Cooley S, Berrien-Elliott MM, et al. First-In-Human phase 1 clinical study of the IL-15 superagonist complex ALT-803 to treat relapse after transplantation. Blood 2018;131:2515-27.

27 Couper KN, Blount DG, Riley EM. II-10: the master regulator of immunity to infection. J Immunol 2008;180:5771-7.

28 Chiba K. Fty720, a new class of immunomodulator, inhibits lymphocyte egress from secondary lymphoid tissues and thymus by agonistic activity at sphingosine 1-phosphate receptors. Pharmacol Ther 2005;108:308-19.

29 Drouillard A, Mathieu A-L, Marçais A, et al. S1Pr5 is essential for human natural killer cell migration toward sphingosine-1 phosphate. J Allergy Clin Immunol 2018;141:2265-8.

30 Jenne CN, Enders A, Rivera R, et al. T-bet-dependent S1P5 expression in NK cells promotes egress from lymph nodes and bone marrow. J Exp Med 2009;206:2469-81.

31 Mikucki ME, Fisher DT, Matsuzaki J, et al. Non-Redundant requirement for CXCR3 signalling during tumoricidal T-cell trafficking across tumour vascular checkpoints. Nat Commun 2015;6:7458.

32 Slaney CY, Kershaw MH, Darcy PK. Trafficking of T cells into tumors. Cancer Res 2014;74:7168-74.

33 Grégoire C, Chasson L, Luci C, et al. The trafficking of natural killer cells. Immunol Rev 2007;220:169-82. 
34 Liu B, Kong L, Han K, et al. A novel fusion of ALT-803 (interleukin (IL)-15 superagonist) with an antibody demonstrates antigen-specific antitumor responses. J Biol Chem 2016;291:23869-81.

35 Vincent M, Bessard A, Cochonneau D, et al. Tumor targeting of the IL-15 superagonist RLI by an anti-GD2 antibody strongly enhances its antitumor potency. Int J Cancer 2013;133:757-65.

36 Beha N, Harder M, Ring S, et al. IL15-based trifunctional antibodyfusion proteins with costimulatory TNF-superfamily ligands in the single-chain format for cancer immunotherapy. Mol Cancer Ther 2019;18:1278-88.

37 Johnson ML, Braiteh F, Grilley-Olson JE, et al. Assessment of subcutaneous vs intravenous administration of anti-PD-1 antibody PF-06801591 in patients with advanced solid tumors: a phase 1 dose-escalation trial. JAMA Oncol 2019;5:999-1007.

38 Davies A, Merli F, Mihaljević B, et al. Efficacy and safety of subcutaneous rituximab versus intravenous rituximab for first-line treatment of follicular lymphoma (SABRINA): a randomised, openlabel, phase 3 trial. Lancet Haematol 2017;4:e272-82.

39 Di Scala M, Gil-Fariña I, Olagüe C, et al. Identification of IFN$\gamma$-producing $T$ cells as the main mediators of the side effects associated to mouse interleukin-15 sustained exposure. Oncotarget 2016;7:49008-26.

40 Guo Y, Luan L, Rabacal W, et al. II-15 Superagonist-Mediated immunotoxicity: role of NK cells and IFN- $\gamma$. J Immunol 2015;195:2353-64.

41 Dougan M, Ingram JR, Jeong H-J, et al. Targeting cytokine therapy to the pancreatic tumor microenvironment using PD-L1-Specific VHHs. Cancer Immunol Res 2018;6:389-401.

42 Neri D, Sondel PM. Immunocytokines for cancer treatment: past, present and future. Curr Opin Immunol 2016;40:96-102.
43 Lugli E, Goldman CK, Perera LP, et al. Transient and persistent effects of IL-15 on lymphocyte homeostasis in nonhuman primates. Blood 2010;116:3238-48.

44 Mathios D, Park C-K, Marcus WD, et al. Therapeutic administration of IL-15 superagonist complex ALT-803 leads to long-term survival and durable antitumor immune response in a murine glioblastoma model. Int J Cancer 2016;138:187-94.

45 Maj T, Wang W, Crespo J, et al. Oxidative stress controls regulatory T cell apoptosis and suppressor activity and PD-L1-blockade resistance in tumor. Nat Immunol 2017;18:1332-41.

46 Suarez GV, Melucci Ganzarain CDC, Vecchione MB, et al. PD-1/PDL1 Pathway Modulates Macrophage Susceptibility to Mycobacterium tuberculosis Specific CD8 ${ }^{+}$T cell Induced Death. Sci Rep 2019;9:187.

47 Bellora F, Castriconi R, Dondero A, et al. The interaction of human natural killer cells with either unpolarized or polarized macrophages results in different functional outcomes. Proc Natl Acad Sci U S A 2010;107:21659-64.

48 Cao L, Che X, Qiu X, et al. M2 macrophage infiltration into tumor islets leads to poor prognosis in non-small-cell lung cancer. Cancer Manag Res 2019;11:6125-38.

49 Waniczek D, Lorenc Z, Śnietura M, et al. Tumor-Associated macrophages and regulatory $T$ cells infiltration and the clinical outcome in colorectal cancer. Arch Immunol Ther Exp 2017;65:445-54.

50 Ballbach M, Dannert A, Singh A, et al. Expression of checkpoint molecules on myeloid-derived suppressor cells. Immunol Lett 2017;192:1-6. 